\title{
Influência do casquete (com ou sem contato cervical com a estrutura moldada) e da moldeira de estoque, para um único elastômero, sobre a precisão dimensional de troquéis de um gesso do tipo IV.
}

\section{André Tomazini Gomes de Sá}

\begin{abstract}
Dissertação apresentada à Faculdade de Odontologia de Bauru, da Universidade de São Paulo, como parte dos requisitos para obtenção do título de Mestre em Odontologia, na área de Dentística, opção Materiais Dentários.
\end{abstract}




\section{Influência do casquete (com ou sem contato cervical com a estrutura moldada) e da moldeira de estoque, para um único elastômero, sobre a precisão dimensional de troquéis de um gesso do tipo IV.}

\section{André Tomazini Gomes de Sá}

Dissertação apresentada à Faculdade de Odontologia de Bauru, da Universidade de São Paulo, como parte dos requisitos para obtenção do título de Mestre em Odontologia, na área de Dentística, opção Materiais Dentários.

Orientador: Prof. Dr. César Antunes de Freitas 
Gomes de Sá, André Tomazini

G585i Influência do casquete (com ou sem contato cervical) com a estrutura moldada) e da moldeira de estoque, para um único elastômero, sobre a precisão dimensional de troquéis de um gesso do tipo IV.I André Tomazini Gomes de Sá. - Bauru, 2003. 67p.; il.; $30 \mathrm{~cm}$.

Dissertação (Mestrado) - Faculdade de Odontologia de Bauru, Universidade de São Paulo.

Orientador: Prof. Dr. César Antunes de Freitas.

Autorizo, exclusivamente para fins acadêmicos e científicos, a reprodução total ou parcial desta dissertação, por processos fotocopiadores e outros meios eletrônicos.

Assinatura:

Data: 


\title{
André Tomazini Gomes de Sá
}

\author{
DADOS CURRICULARES
}

$14 / 08 / 1965$

$1984-1988$

$1991-1992$

1998

2002

$2001-2003$
Nascimento em Londrina-PR, filho de

Aloísio Gomes de Sá e Helena Maria

Tomazini de Sá.

Curso de graduação em Odontologia pela Faculdade de Odontologia da Universidade Estadual de Londrina (UEL).

Residência Odontológica sob a forma de Especialização, na área de Prótese Dental, pela Faculdade de Odontologia de Ribeirão Preto,(FORPUSP).

Professor do Curso de Odontologia da Universidade Norte do Paraná (UNOPAR).

Professor do Curso de Odontologia da Universidade Estadual de Londrina (UEL).

Curso de Pós-graduação (Mestrado),na área de Dentística, opção Materiais Dentários, pela Faculdade de Odontologia de Bauru (FOB-USP). 


\section{Dedicatória}

Ao meu pai Aloísio Gomes de Sá (em memória).

À minha mãe Helena Maria Tomazini de Sá.

Ao meu irmão Fábio Tomazini Gomes de Sá.

À minha mulher Tânia Christina Simões.

À minha filha Beatriz Simões Gomes de Sá.

À minha prima Helena Tomazini de Carvalho.

À minha avó Luzia Romero Tomazini (em memória).

Ao meu avô Marcos Tomazini (em memória).

Ao meu sogro Eurípedes Simões (em memória).

A Kyohaku Shi.

E a todos os meus antepassados. 


\section{Agradecimentos}

Ao meu muito caro e muito venerado*

Mestre e amigo

César Antunes de Freitas

com os sentimentos

da mais profunda humildade

${ }^{\star} \mathrm{C}$. Baudelaire

Agradeço especialmente à minha mãe Helena e à minha mulher Tânia, pelo apoio irrestrito e inestimável.

E agradeço também com os sentimentos de admiração e respeito:

Aos Professores da Disciplina de Materiais Dentários da Faculdade de Odontologia de Bauru-USP, Profs. Drs. Paulo Afonso Silveira Francisconi e Paulo Amarante de Araújo.

Ao Professor da Disciplina de Materiais Dentários, da Faculdade de Odontologia de Londrina-UEL, Prof. Dr. Guilherme Augusto de Barros Nolasco.

Aos Professores da Faculdade de Odontologia de Bauru-USP: Profs. Drs. Odila Pereira da Silva Rosa, José Mondelli, José Roberto Pereira Lauris, Alberto Consolaro e José Henrique Rubo.

Aos Professores do Departamento de Dentística, Materiais Dentários e Endodontia da Faculdade de Odontologia de Bauru-USP. 
Aos Professores da Faculdade de Odontologia de Londrina: Yoneo Takahashi, Fátima Cristina de Sá, Alcides Gonini, Wagner Ursi, Walter Bush Pereira, Raul Hauenstein, Jorge Augusto, René Fabre, Antonio Carrilho, Vera Pelanda, Marcos Frossard, Amaury Silveira de Moraes e Pedro Carlos Ferreira Tonani.

Ao Professor da Faculdade de Odontologia de Lins: Prof. Dr. Marco Polo Marchese.

A todos aqueles que foram meus Professores, desde o início.

Aos funcionários da Disciplina de Materiais Dentários da Faculdade de Odontologia de Bauru-USP: Alcides, Sandra e Lourisvalda.

Aos funcionários da Portaria, da Biblioteca e da Secretaria de Pós Graduação da Faculdade de Odontologia de Bauru-USP.

Aos funcionários da Faculdade de Odontologia de Bauru-USP.

Aos meus colegas de curso: Anderson, Humberto, Renato, Henrique, Carla, Willian, Rosa, Luísa e Daniela.

Aos meus familiares: Olga, Marcolina, Alcides e Aurora.

À dona Maria Socateli e à Matilde.

Aos amigos que sabem quem eu sou.

À Faculdade de Odontologia de Bauru, ao CNPq e ao Governo do Estado de São Paulo. 


\section{Sumário}

RESUMO

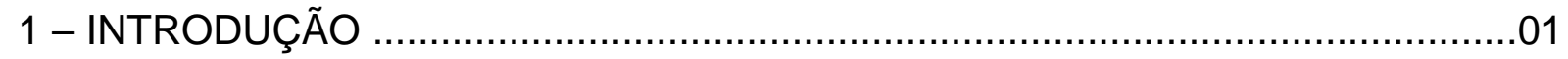



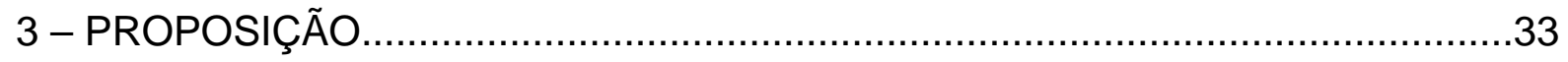

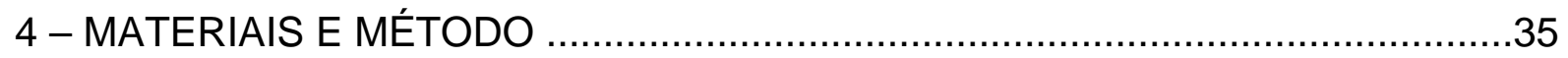

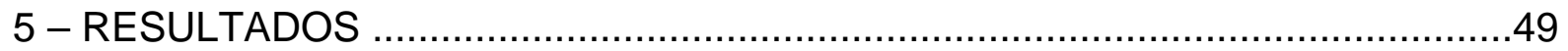

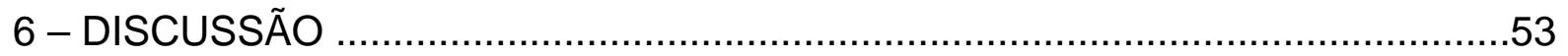



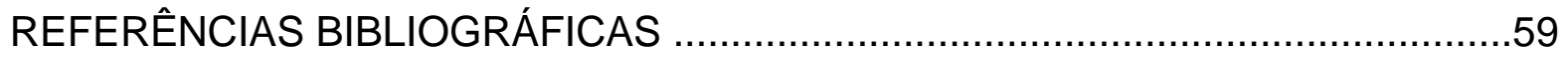

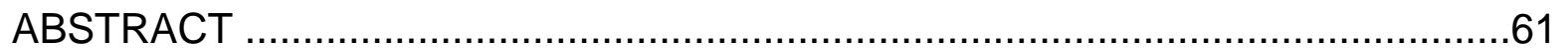


Resumo 


\section{Resumo}

O objetivo no presente trabalho foi avaliar a fidelidade dimensional de troquéis

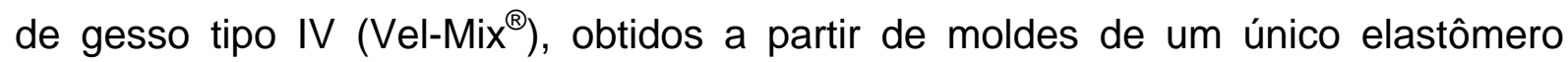
(Impregum ${ }^{\circledR} \mathrm{F}$ ), utilizando-se duas diferentes técnicas de moldagem (com casquete ou com moldeira de estoque). A fidelidade de cada troquel obtido foi avaliada através de uma coroa-padrão, a qual encaixava-se com alta precisão ao troquelpadrão, o qual era a estrutura original a ser moldada. Assim foram compostos os 4 seguintes grupos, com o aquecimento do molde não tendo sido efetuado apenas no primeiro deles: 1- do casquete de resina, sem contato com a porção cervical do troquel-padrão (Cstsa); 2- do casquete, também sem o referido contato (Cstca) ; 3novamente do casquete, agora com contato (Cctca) e 4-. da moldeira de estoque perfurada (Mca). Com base nos resultados encontrados nas condições estabelecidas, após o respectivo tratamento estatístico, foi possível concluir que: 1 o pior desempenho ocorreu com a moldeira perfurada, com um desajuste médio da ordem de 397, 70 micrometros; 2 - o casquete com toque e com aquecimento (desajuste médio de 85,37 micrometros) apresentou desempenho semelhante ao do casquete sem toque e sem aquecimento (desajuste médio de 102,38 micrometros) e 3 - o melhor desempenho ocorreu com o casquete sem toque e com aquecimento, com um desajuste médio de 0,03 micrometros. 
Introdução 


\section{1- Introdução.}

Quando um dente está preparado para receber uma coroa total, a precisão do respectivo modelo de gesso é dependente de vários fatores, dentre os quais encontram-se várias características do material de moldagem utilizado.

Os elastômeros, materiais de moldagem de uso consagrado em Odontologia, são polímeros, cujas grandes moléculas unem-se por ligações cruzadas para formar uma estrutura tridimensional elástica.

Um elastômero pode pertencer a um dos seguintes grupos químicos: do polissulfeto, das siliconas (uma de polimerização por condensação e outra por adição) e do poliéter. Dentre eles, apenas este último foi desenvolvido especificamente para uso odontológico, em 1966.

Numa técnica de moldagem em que é usada uma moldeira total ou parcial, a espessura de elastômero em seu interior é variável em pontos diversos, o que já torna esperada a obtenção de um molde com grandes distorções, quer seja ela feita por uma técnica na qual exista uma única fase de moldagem (moldagem única) ou duas (técnica da dupla moldagem).

Uma técnica de moldagem de boa aceitação é aquela na qual um casquete de resina acrílica (individualizado) é preenchido com o elastômero, para então ser posicionado e comprimido sobre o dente preparado. Esta técnica é interessante pela boa precisão dos moldes obtidos, assim como pela economia de material. Como conseqüência da proximidade do casquete com o dente preparado, eventualmente há o contato de parte de suas superfícies. A diferença entre uma técnica que permita esta relação, e outra que evite o toque, é sutil. 
Assim, torna-se necessário pesquisar as eventuais conseqüências negativas que a grande espessura de elastômero no interior da moldeira de estoque, e o contato do casquete, diretamente com algum local da estrutura dentária, possam acarretar à precisão dos respectivos troquéis obtidos. 
Revisão da Literatura 


\section{2- Revisão da Literatura.}

Para PHILLIPS ${ }^{26}$ (1959), o uso de uma espessura mínima de material à base de borracha, necessária para obter a impressão, irá minimizar a ocorrência de bolhas e a contração de polimerização; sempre que possível, a espessura do material não deveria exceder $2 \mathrm{~mm}$. Esta necessidade de volume mínimo do material reforça a importância de uma moldeira selecionada corretamente; deve ser rígida e ajustada de maneira que promova uma distribuição uniforme do elastômero em torno da cavidade preparada. O material de impressão deve estar firmemente preso à moldeira (senão irá distorcer durante a remoção), através de adesivos, que costumam funcionar bem.

Em 1965, CANNISTRACI ${ }^{08}$ descreveu uma técnica de obtenção de moldeiras de acrílico que combinaria as vantagens da técnica dos anéis de cobre com a dos hidrocolóides reversíveis. Consistia em aproveitar uma já existente técnica de construção de coroas acrílicas provisórias; no interior de um molde (de alginato) dos dentes a serem preparados depositava-se uma fina camada de resina com o auxílio de um pincel, formando assim uma pequena casca (casquete) com a forma de um dente; depois da polimerização esta casca era removida do interior do molde, preenchida com uma porção de resina e posicionada sobre o dente; removidos os excessos, e com a peça ajustada, $1 \mathrm{~mm}$ de sua porção interna era removido para convertê-la em uma moldeira. Estava então pronta para que fosse aplicado o adesivo e preenchida com o elastômero. O autor ressaltou que todos os passos são importantes para 
o sucesso de uma restauração protética, inclusive a qualidade tanto da preparação do dente como da saúde gengival. Relatou também que à sua época havia muita controvérsia sobre quanto tempo um molde de elastômero poderia ser mantido até que fosse preenchido com gesso. Não há dúvida, disse ele, de que quanto antes for preenchido, menor será a possibilidade de alteração dimensional; entretanto, afirma que não tem encontrado alteração de significância clínica dentro de um prazo de 24 horas. Outro aspecto importante acusado foi o afastamento gengival obtido com esta técnica, economizando tempo e facilitando o trabalho clínico.

BRADEN; CAUSTON; CLARKE ${ }^{07}$, em 1972, fizeram um estudo sobre a composição química e sobre as características físicas dos poliéteres. Os aspectos abordados foram: análise química, reologia da pasta base, tempo de presa, absorção de água, alteração dimensional, expansão térmica e propriedade viscoelástica. Concluíram que o material é de manipulação fácil, sem odor e polimeriza mais rapidamente do que os polissulfetos; a pasta base exibe viscosidade não Newtoniana; o alto módulo de elasticidade combinado com a resistência ao rasgamento moderada significa que é preciso cuidado na remoção de moldes extensos e complicados; o material possui boa estabilidade dimensional em ar, entretanto tem alta afinidade pela água; na prática, a estabilidade dimensional em contato com a água é afetada pela absorção desta, e pela extração de substâncias solúveis em água; como o contato com a água ou meios úmidos é inevitável, a suscetibilidade a estes efeitos é a principal desvantagem do material; a expansão térmica é maior para os 
poliéteres do que para outros elastômeros, provavelmente porque os poliéteres possuem baixo conteúdo orgânico.

BELL; FRAUNHOFER ${ }^{04}$ (1975), ao final de um trabalho de revisão sobre os materiais elastoméricos de impressão, fizeram uma série de recomendações a fim de se obter máxima precisão dos moldes: 1) é indicado para todos os materiais, um aumento de 50\% sobre o tempo de presa recomendado pelos fabricantes; 2) moldeiras padronizadas são preferíveis às de estoque e deveriam ser utilizadas sempre que possível; deveriam permitir uma espessura uniforme do material de impressão (uma espessura de 2 a 4 mm parece ser ótima); deveriam também ser rígidas, não susceptíveis à distorção; 3) idealmente, o molde deveria ser preenchido com gesso 30 minutos depois de obtido, para que pudesse ocorrer a recuperação elástica do material; para um tempo de espera maior, o poliéter parece ser o mais estável por longos períodos, desde que guardado em condição sem umidade; 4) parece haver pouca diferença entre as técnicas de dupla mistura e de reembasamento, desde que meios de extravasamento sejam utilizados nesta última; 5) troquéis obtidos de segundos vazamentos são sempre menos precisos do que os primeiros, independente da técnica, e deveriam ser utilizados apenas para posicionamento; as margens das coroas deveriam ser sempre ajustadas no primeiro troquel; 6) alta umidade ou contaminação do material com água acelera sua presa; 7) a umidade ambiente afeta o material polimerizado e é um fator importante na precisão dos troquéis, particularmente se o molde for deixado por algum tempo até ser preenchido com gesso; 8) em condições de alta umidade, os materiais de escolha parecem ser aqueles do 
grupo dos polissulfetos; 9) os moldes de poliéteres nunca deveriam ser mantidos em condições de alta umidade, inclusive em uma caixa fechada junto com um molde de alginato úmido; 10) a manutenção das siliconas em condição de umidade parece prevenir a perda de constituintes voláteis, e a contração de polimerização é compensada pela água absorvida; para este material tanto as condições de alta ou baixa umidade causarão perda de precisão.

Em 1977, a entidade AMERICAN DENTAL ASSOCIATION ${ }^{01}$ (ADA) publicou uma revisão de sua especificação $n^{\circ} 19$, relativa aos materiais de impressão elastoméricos não aquosos utilizados em Odontologia; são classificados como tipos I, II e III de acordo com suas propriedades elásticas e com a alteração dimensional depois de polimerizados. Cada tipo é também classificado de acordo com sua viscosidade aparente e projeção de uso. Os materiais envolvidos são os polissulfetos, os polisiloxanos, os poliéteres ou outros materiais não aquosos capazes de reagirem para formarem materiais borrachóides adequados para impressão. A norma estabelece algumas exigências relativas, por exemplo, ao tempo de trabalho, compatibilidade com o gesso e alteração dimensional; aponta as condições necessárias para os procedimentos de ensaio, como por exemplo, a temperatura $\left(23 \pm 1{ }^{\circ} \mathrm{C}\right)$ e a umidade (50 $\pm 5 \%)$ ambiente; fornece algumas definições importantes como: tempo de mistura é aquele requerido para se fazer uma mistura homogênea e uniformemente colorida dos componentes; tempo de trabalho é aquele medido a partir do início da mistura até que a viscosidade aparente aumente até certo nível definido pelos procedimentos desta norma; e o tempo de presa é definido como transitório do início da mistura até que as propriedades plásticas que 
permitem a moldagem sejam perdidas, e as propriedades elásticas que permitem a remoção do material de regiões retentivas sejam adquiridas.

Em 1979, EAMES et al. ${ }^{14}$. avaliaram a influência do volume de materiais de impressão sobre a precisão dos moldes obtidos. Utilizaram um troquel de aço inoxidável que representava um dente preparado para receber uma coroa total, com 12 graus de inclinação em suas paredes. As moldeiras foram construídas com material plástico em um equipamento de moldagem a vácuo, e reservavam 2, 4 e $6 \mathrm{~mm}$ de espaço para o material de impressão. Todas as moldagens foram executadas de acordo com as instruções dos fabricantes. $O$ conjunto do molde com o troquel era colocado em água a $37^{\circ} \mathrm{C}$ para polimerização estes eram separados em seguida. A medição das distâncias entre linhas impressas no molde (presentes, portanto, no troquel de aço) foram feitas com microscópio de leitura linear e acuidade de $5 \mu \mathrm{m}$. Além da leitura imediata, os moldes foram reservados por 24 horas em temperatura ambiente, tempo no qual foi realizada nova leitura. Quinze espécimes dos seguintes materiais (cinco para cada grupo representado pelo volume do material) foram testados: três polissulfetos, dois poliéteres e duas siliconas. Para simular uma condição clínica, nove espécimes (três de cada espessura) de três materiais, selecionados entre aqueles já citados, foram preenchidos com gesso (VelMix®). Copings foram encerados diretamente sobre o troquel de aço e fundidos. Em seguida foram assentados os troqueis de gesso e o nível de adaptação entre ambos foi verificado com a medição da fenda presente na região cervical. Os autores observaram que os moldes com $2 \mathrm{~mm}$ de espessura do elastômero demonstraram melhor precisão do que aqueles com 
4 e $6 \mathrm{~mm}$; afirmaram inclusive que a desadaptação das peças fundidas obtidas a partir dos moldes de 4 e 6 mm não seria aceitável clinicamente.

Para que se obtenham peças protéticas bem adaptadas, a precisão deve ser alcançada desde a impressão até a fundição. Com esta afirmação, EAMES et al. ${ }^{15}$, em 1979, fizeram a introdução de um trabalho onde 34 elastômeros, de 13 fabricantes, foram examinados em relação à precisão e à estabilidade dimensional. Cada material foi testado de acordo com a especificação $\mathrm{n}^{\circ} 19$ da American Dental Association. A porcentagem da alteração dimensional negativa foi medida nos tempos de 30 minutos e 24 horas a partir do início da espatulação. Adicionalmente, 20 impressões foram obtidas simulando condições clínicas de utilização sobre um troquel de aço que representava um dente preparado para receber uma coroa total; as moldeiras foram fabricadas com um material processado termicamente, e promoviam um espaço de 2,4 mm para o material de impressão. Os moldes eram colocados em banho a $32 \pm 2{ }^{\circ} \mathrm{C}$, por 3 minutos além do recomendado pelo fabricante; o gesso para troquel foi espatulado a vácuo, por 30 segundos, e inserido nos moldes nos tempos de 30 minutos e 24 horas. A precisão dos troquéis de gesso foi determinada por peças fundidas que tinham sido construídas sobre o troquel de aço e que eram assentadas sobre os troquéis de gesso; a fenda presente entre as peças fundidas e os troquéis era medida em um microscópio. A contração que todos os materiais apresentaram aos 30 minutos variou de 0,11 a 0,45\%, e com 24 horas a contração foi de 0,18 a 0,84\%. Os poliéteres e os polissulfetos foram geralmente mais estáveis e as siliconas de condensação menos estáveis. As novas siliconas de adição exibiram as menores alterações, com 
equivalência estatística aos poliéteres. Com base nos resultados observados, os autores concluíram que quando os moldes são preenchidos imediatamente com gesso muitos dos materiais avaliados exibiram características semelhantes de estabilidade, e os dentistas deveriam fazer sua escolha por outros motivos. Em situações que impedem o vazamento imediato do gesso, apenas os materiais mais estáveis deveriam ser utilizados.

MCCABE; STORER ${ }^{23}$, em 1980, examinaram as propriedades dos materiais de impressão elastoméricos. Dividiram o estudo em 4 categorias: característica da polimerização, que tem grande influência sobre a escolha do produto pelos clínicos; alterações dimensionais dependentes do tempo, inclusive o coeficiente de expansão térmica e a contração de polimerização; propriedades mecânicas como resistência à compressão, resistência ao rasgamento e elasticidade; capacidade do material para copiar regiões retentivas. Os materiais empregados neste estudo foram os polissulfetos, a siliconas de adição e de condensação e os poliéteres. A partir dos resultados observados concluíram que: 1) os requisitos de um material de impressão para coroas totais e diferentes tipos de preparações são variáveis e alguns tipos de materiais são mais adequados do que outros para determinadas aplicações; 2) preparações para coroas totais requerem um material com grande resistência ao rasgamento, para que possam copiar regiões sub-gengivais retentivas; os polissulfetos são mais adequados para esta aplicação; 3) para preparações do tipo inlay, um material com boa propriedade elástica é necessário; as siliconas oferecem as melhores chances para estas circunstâncias; 4) para estruturas que abrangem todo o arco, a escolha da moldeira é mais importante do que o 
material de impressão; 5) os poliéteres oferecem a melhor combinação de propriedades; entretanto é muito rígido quando polimerizado e poderia haver dificuldade para removê-lo de retenções severas; 6) boa adesão do material à moldeira é essencial para evitar distorções; 7) a busca por um material perfeitamente preciso é contra-produtivo pois alguma contração é necessária para compensar parcialmente a contração térmica da fundição e permitir o espaço para o material de cimentação.

CIESCO et al. ${ }^{10}$, em 1981, compararam a estabilidade dimensional e a precisão de cinco elastômeros: dois polissulfetos (Permlastic ${ }^{\circledR}$ e Omniflex®), uma silicona de adição (President $®)$, uma silicona de condensação (Accoe $\left.{ }^{\circledR}\right)$ e um poliéter (Impregum®). Um troquel circular de aço (semelhante àquele descrito pela American Dental Association em sua especificação n¹9) foi utilizado para comparar as amostras, em temperatura e umidade ambiente média de $22^{\circ} \mathrm{C}$ e $59 \%$ respectivamente. A avaliação dos moldes foi feita com a utilização de um microscópio, pela medição de linhas impressas em sua superfície interna tanto logo após sua remoção do troquel, como depois de 1, 24, 48 e 72 horas e também depois de 1 semana. De acordo com os autores, os elastômeros foram avaliados de modo que simulassem condições clínicas de uso, inclusive com a imersão dos moldes em água a $32{ }^{\circ} \mathrm{C}$. O troquel possuía também um anel que sobre ele se encaixava atuando como uma moldeira ou recipiente. Em uma segunda etapa do trabalho os materiais foram avaliados com a utilização de moldeiras padronizadas de plexiglass e dos respectivos adesivos fornecidos pelos fabricantes. As conclusões dos autores foram as seguintes: 1) todos os materiais de impressão que foram avaliados 
imediatamente e na condição com moldeira padronizada e adesivos, demonstraram resultados superiores quando comparados com os grupos nos quais não se utilizou moldeira e adesivo; 2) o poliéter conduziu a resultados superiores com ou sem moldeiras padronizadas quando comparado com outros elastômeros, seguido pelas siliconas de adição, pelos polissulfetos e pelas siliconas de condensação, respectivamente.

LACY et al. ${ }^{18}$., em 1981, fizeram um estudo para examinar a estabilidade dimensional de quatro classes de materiais de impressão, assim como diferentes marcas comerciais (na parte I deste trabalho foram avaliadas apenas as siliconas de condensação), utilizando dois tipos de moldeiras: sistema massa densa e pasta fluida com moldeira de estoque e outra com moldeira padronizada de acrílico, onde a pasta fluida (com 1 ou 2 viscosidades diferentes) do elastômero é retida por adesivos. O volume de material fluido no interior do molde era diferente para cada técnica: $0,5 \mathrm{~mm}$ para a primeira e 1,5 para esta feita com moldeira de acrílico. Três moldes de cada elastômero foram feitos em temperatura ambiente de $21{ }^{\circ} \mathrm{C}$, e preenchidos com gesso para troquel, que era espatulado manualmente por 15 segundos. Estes troquéis iniciais eram removidos do molde depois de 15 minutos; os moldes eram então sucessivamente preenchidos com gesso nos seguintes intervalos de tempo: 30 minutos, 1, 2, 4, 24, 48 e 96 horas. O troquel original era feito de liga de alumínio torneado e simulava um molar preparado para receber uma coroa total; sua superfície oclusal era marcada para indicar as faces buco-lingual e mesio-distal. As conclusões extraídas pelos autores foram as seguintes: 1) embora as siliconas de condensação possam ser usadas para produzir troquéis 
múltiplos a partir de um único molde, pode-se contar com mudanças dimensionais nos troquéis produzidos a partir de sucessivos vazamentos; 2) sistemas de massa e pasta exibiram comportamento variável entre diferentes marcas; algumas delas produziram uma série de troquéis com diâmetro aumentado acima do período de 4 dias, enquanto outras produziram troquéis nos quais o diâmetro diminuiu de acordo com os sucessivos vazamentos; 3) moldes de siliconas de pastas fluidas obtidos com moldeiras de resina acrílica produziram troquéis que apresentaram aumento no diâmetro com o tempo; 4) sistemas de massa e pasta, de modo geral, apresentaram troquéis com maior excentricidade do que aqueles obtidos com moldeira de acrílico e pasta fluida, mas houve exceções entre as marcas testadas; 5) pareceu não haver diferença de comportamento entre as técnicas de dupla mistura e de uma fase das siliconas de condensação; 6) para obter máxima precisão, os moldes de siliconas de condensação devem preenchidos com gesso o mais rápidamente possível.

LACY et al. ${ }^{19}$, em 1981, fizeram um estudo com o objetivo de comparar a precisão e a estabilidade dimensional de alguns elastômeros (representativos dos polissulfetos, dos poliéteres e dos polivinilsiloxanos), pela análise do índice e da magnitude da mudança no tamanho dos modelos de gesso obtidos seqüencialmente em 96 horas. Utilizaram duas técnicas de impressão: uma na qual se usa a massa e a pasta do elastômero, e outra com apenas a pasta. Fazendo uma comparação com os resultados obtidos na parte I (na qual foram utilizados quatro tipos de siliconas de condensação) concluíram que: os polivinilsiloxanos são os elastômeros mais estáveis entre aqueles avaliados; a 
precisão e consistência são melhores mantidos pelo uso de moldeiras individuais e de adesivos para reter os polivinilsiloxanos; os modelos obtidos a partir dos polissulfetos unidos às moldeiras individuais apresentaram um aumento progressivo em seu diâmetro, e que quando avaliados com mais de 4 dias não são mais nem menos precisos do que aqueles obtidos com as siliconas de condensação; os poliéteres possuem estabilidade intermediária entre os polissulfetos ou siliconas de condensação e os polivinilsiloxanos, quando a técnica envolve moldeira individual com adesivo; o sistema massa/pasta dos polivinilsiloxanos pode apresentar alguma perda de precisão nos modelos obtidos por vazamentos múltiplos, depois de 2 e 4 dias; parece não haver diferenças acentuadas. entre as técnicas de simples misturas, para os polissulfetos, quando se utiliza, para ambos, moldeira individual de acrílico.

FARAH et al. ${ }^{16}$ (1981), afirmaram em um trabalho de revisão dos materiais elastoméricos que estes deveriam ser dimensionalmente precisos e estáveis, polimerizar em tempo razoavelmente curto, e possuir um tempo de validade adequado; além disto deveriam ser de fácil manipulação e bem aceitos pelos pacientes. Ao final do estudo fizeram recomendações sobre alguns procedimentos necessários para se alcançar as propriedades ótimas dos elastômeros, que são: misturar os materiais vigorosamente até que se obtenha uma massa homogênea livre de veios; utilizar moldeiras padronizadas, as quais deveriam ser rígidas e permitir espaço livre de $2 \mathrm{~mm}$ para o material de impressão (para os poliéteres uma espessura de $4 \mathrm{~mm}$ ou mais é preferível); respeitar o tempo de presa recomendado pelo fabricante; depois de remover o molde da boca aguardar 15 minutos para fazer o troquel, para que 
ocorra a recuperação elástica do material de impressão (que é menos crítica para os poliéteres e para as siliconas de adição); como os troquéis obtidos do segundo vazamento são menos precisos, completar o enceramento e o acabamento da peça sobre o primeiro troquel; armazenar os moldes de poliéter em local seco; poliéteres (quando armazenados corretamente) e siliconas de adição suportam melhor o tempo de transporte, porém é melhor que o molde seja preenchido com gesso antes; para moldes de toda arcada ou de vários dentes preparados, o melhor material é o polissulfeto, leve ou regular, seguido das siliconas de adição e das siliconas de condensação, e por último os poliéteres (esta ordem está baseada principalmente na capacidade do material escoar e na sua resistência ao rasgamento); o adesivo de um material não deveria ser utilizado com outro elastômero.

PAGNIANO et al. ${ }^{25}$, em 1982, realizaram um estudo para verificar a mudança na dimensão linear de 4 marcas comerciais de resinas acrílicas apropriadas para construção de moldeiras padronizadas. Medições contínuas por 24 horas foram feitas para determinar o período no qual mais mudanças ocorreriam. Outro aspecto estudado, foi a alteração apresentada pelos materiais quando colocados em água em ebulição. Diante dos resultados observados, concluíram que quanto maior o período de tempo aguardado para que uma moldeira de resina acrílica seja utilizada, mais estável será; idealmente esperando pelo menos 9 horas depois de fabricadas, os materiais testados se apresentaram comparativamente estáveis; se for necessário utilizar a moldeira logo após ter sido fabricada, deveria ser colocada em água em ebulição por 5 minutos, e então esfriada. 
Em 1983, CLANCY; SCANDRETT; ETTINGER ${ }^{11}$ estudaram a estabilidade dimensional de três elastômeros: um poliéter (Polygel), uma silicona de adição (Reprosil), e uma silicona de condensação (Elasticom). Os intervalos de tempo para o preenchimento do molde com o gesso foram: imediatamente, após 4, 24 e 48 horas, e 1, 2, 3 e 4 semanas. Os materiais de moldagem foram manipulados de acordo com as instruções dos fabricantes e colocados na moldeira (que se ajustava a um bloco cilíndrico de aço inoxidável), entre 1 e 5 minutos depois do início da mistura.O elastômero ainda fluido era coberto por uma folha de polietileno e uma placa de vidro, e o conjunto era imediatamente imerso em água à temperatura de $32 \pm 2^{\circ} \mathrm{C}$, situação em que permanecia pelo tempo de polimerização indicado pelo respectivo fabricante. Os 75 moldes assim obtidos foram analisados com 0 auxílio de um microscópio e de um computador. Os autores afirmaram não haver mudança dimensional significante com o Reprosil e o Polygel, nos tempos estudados, tendo ambos apresentado pequena variação dimensional até a quarta semana. Já o Elasticom apresentou mudança significante em sua dimensão no tempo de 4 horas, e nos tempos subseqüentes. Notaram também que depois de 4 semanas o Reprosil apresentou a melhor reprodução de detalhes de superfície, e que o Elasticom perdeu muitos de seus detalhes já no tempo de 24 horas.

VALDERHAUG; FLOYSTRAND ${ }^{32}$, em 1984, fizeram um trabalho com o propósito de avaliar e comparar a estabilidade dimensional de moldes obtidos com moldeiras padronizadas de acrílico e moldeiras de estoque metálicas. Dois modelos mestre foram fabricados com metal; ambos possuíam dentes 
pilares(com superfície oclusal plana) na região de caninos e primeiro molares. Dois sulcos com $5 \mu \mathrm{m}$ de largura gravados (em forma de cruz) na superfície oclusal tornavam possível a medição(com o auxílio de um microscópio) das distâncias entre os pilares tanto nos moldes como nos modelos. O projeto experimental do trabalho incluiu: dois tipos de moldeiras(estoque metálica, e padronizada de acrílico); dois tipos de materiais de impressão(Impregum® e Xantopren ${ }^{\circledR}$ de consistência média e leve); dois tipos de situação clínica(distância entre os pilares); tempo variado de estocagem dos moldes. Três moldagens foram feitas para cada combinação, produzindo um total de 24 moldes. As medições foram feitas imediatamente depois de removidos os moldes do modelo mestre, e depois de 1 e 24 horas. Todos os procedimentos foram executados em laboratório com temperatura $\left(21^{\circ} \mathrm{C}\right)$ e umidade $(50 \%)$ controladas. Os resultados revelaram não haver diferença estatística entre as distâncias observadas nos moldes obtidos com os dois diferentes tipos de elastômeros. Uma objeção relatada pelos autores é a de que as medições foram limitadas ao plano horizontal, não fornecendo portanto qualquer informação quanto à precisão tri-dimensional dos moldes. Afirmaram também que as pequenas diferenças dimensionais por eles observadas entre os poliéteres e as siliconas estão em oposição àquelas observadas por outros autores.

Em 1985, ARAÚJO; JÖRGENSEN ${ }^{02}$ utilizaram um troquel de aço com a forma de um tronco de cone para determinar a influência do volume do elastômero no interior do molde, e também do tamanho da retenção cervical sobre a precisão dos troquéis de gesso obtidos. Tal troquel possuía três anéis 
que ajustavam a altura da região retentiva (correspondente à do sulco gengival) em 3, 2 e $1 \mathrm{~mm}$. As diferentes espessuras (1, 2, 3 e $4 \mathrm{~mm})$ do material de impressão eram determinadas pelos diferentes diâmetros internos das moldeiras perfuradas. Os elastômeros e o gesso para troquéis utilizados foram respectivamente: o Permlastic ${ }^{\circledR}$ e o President ${ }^{\circledR}$ ambos de viscosidade regular, e o gesso do tipo IV Duroc ${ }^{\circledR}$. Os materiais foram manipulados de acordo com as instruções dos fabricantes, em ambiente com temperatura controlada (22 \pm 2 $\left.{ }^{\circ} \mathrm{C}\right)$. Imediatamente após a moldagem, o conjunto era colocado em um recipiente com água à temperatura de $37^{\circ} \mathrm{C}$, e ali mantido por quinze minutos contados a partir do início da manipulação do material. Depois de separado do troque-padrão, o molde era mantido em temperatura ambiente por 10 minutos e o gesso vertido em seu interior; duas horas depois, o troquel de gesso era removido do molde e levado ao microscópio para que fossem registradas suas medidas, e comparadas com às do troquel-padrão. Diante dos resultados observados, os autores afirmaram que ambos os fatores analisados afetaram a dimensão dos troquéis de gesso; os dados revelaram que o aumento da espessura do elastômero de 1 para $4 \mathrm{~mm}$ causou uma distorção maior do que o aumento da altura da região retentiva de 1 para $3 \mathrm{~mm}$.

ARAÚJO; JÖRGENSEN ${ }^{03}$, em 1986, estudaram o efeito do reaquecimento de moldes de uma silicona de adição sobre a dimensão de troquéis de gesso. President ${ }^{\circledR}$ regular e Duroc ${ }^{\circledR}$ tipo IV foram utilizados como materiais de impressão e para troquéis respectivamente; o troquel-padrão era feito de aço-cromo com a forma de um tronco de cone que possuía uma região 
retentiva cervical de $1 \mathrm{~mm}$ de altura e $0,5 \mathrm{~mm}$ de profundidade. Os moldes foram obtidos com moldeiras perfuradas cilíndricas, que reservavam 1 e 4 mm de elastômero circundando o troquel-padrão, e $2 \mathrm{~mm}$ entre sua superfície oclusal e a base interna da moldeira. O material de impressão era manipulado em temperatura ambiente de $22^{\circ} \pm 2{ }^{\circ} \mathrm{C}$, e o conjunto transferido para água com temperatura de $37{ }^{\circ} \mathrm{C}$ por 15 minutos. Em um grupo os moldes foram preenchidos com gesso 10 minutos depois de esfriarem a temperatura ambiente, e no outro foi realizado novo aquecimento a $37^{\circ} \mathrm{C}$ por 30 minutos depois de esfriados por 10 minutos. Para os moldes reaquecidos, a água, o gesso e o equipamento de manipulação foram também pré-aquecidos à mesma temperatura. Concluíram que houve maior distorção com o aumento da espessura do elastômero, e que troquéis podem ser fabricados com mínima distorção empregando-se gessos com apropriada expansão de presa e reaquecendo os moldes de siliconas de adição.

Em 1988, SCHELB et al. ${ }^{30}$ avaliaram a compatibilidade de 14 gessos do tipo IV com 3 poliéteres. Quatro amostras de cada uma das combinações possíveis foram produzidas, gerando 168 espécimes. Utilizaram placas de vidro com 2 polegadas quadradas sobre as quais foi riscada uma linha de $20 \mu \mathrm{m}$ de acordo com a especificação $\mathrm{n}^{\circ} 19$ da ADA. Estas placas foram moldadas e os gessos vertidos sobre os moldes obtidos; depois da presa do gesso, os espécimes eram avaliados por três pares de examinadores; cada espécime com uma linha visível em mais de $50 \%$ de seu comprimento foi considerado como "linha presente". Observaram que a linha foi reproduzida em todos os moldes; entretanto apenas $12,1 \%$ foram identificadas nos modelos de gesso e 
das 42 combinações (elastômero/gesso), apenas 19 reproduziram a linha de 20 $\mu \mathrm{m}$. Concluíram que: 1) a capacidade de reprodução de uma linha de $20 \mu \mathrm{m}$ de largura pode ser usada para determinar a compatibilidade entre os poliéteres e os gessos odontológicos; 2) a combinação do Permadyne ${ }^{\circledR} \operatorname{com}$ o Supercal ${ }^{\circledR}$ reproduziu a linha em 100\% das vazes; 3) os fabricantes deveriam identificar os gessos que são compatíveis com os materiais de impressão de sua fabricação.

Em um trabalho de 1988, BOMBERG et al. ${ }^{05}$ avaliaram o efeito de alguns fatores envolvidos na retenção do elastômero no interior da moldeira. Introduziram o assunto relatando a importância dos adesivos e das retenções mecânicas na obtenção de moldes precisos; afirmaram também que os adesivos próprios dos polissulfetos e poliéteres fornecem as maiores forças de adesão do elastômero com a moldeira, e que os adesivos das siliconas de condensação e muitas daquelas utilizadas com as siliconas de adição têm baixos valores de adesão. Os autores fizeram uma série de 60 impressões sobre um modelo montado com dentes extraídos fixados em uma base de gesso; um dos dentes foi preparado para receber uma coroa total fundida, encerada diretamente sobre ele. Quatro tipos de moldeiras (de acrílico ou de estoque, perfurada ou não) combinadas com duas técnicas de moldagem, utilizando ou não os adesivos adequados, foram avaliados a partir de moldes de um único elastômero (Exaflex® regular). O critério de avaliação dos moldes foi a precisão do assentamento da fundição sobre os troquéis de gesso obtidos. Afirmaram, com base em seus resultados, que a associação do adesivo com 
moldeira perfurada conduziu aos melhores resultados, independente do fato das moldeiras serem de estoque ou individuais, ou da técnica de moldagem.

MOJON et al. ${ }^{24}$, em 1990, avaliaram a alteração dimensional de resinas acrílicas utilizadas na Odontologia; analisaram a influência da proporção pó/líquido e compararam duas marcas comerciais disponíveis no mercado (Duralay ${ }^{\circledR}$ e Palavit $G \circledast$ ). Como não havia instruções sobre a proporção pó/líquido em ambos materiais, estabeleceram uma mistura padronizada que era clinicamente apropriada. Para avaliar a influência da relação pó/líquido sobre a alteração dimensional, duas outras proporções foram testadas para cada resina. As primeiras medições foram feitas com um dilatômetro aos 17 minutos após o início da mistura; para as medições seguintes um transdutor (desenvolvido para medir alterações dimensionais do amálgama) registrava a alteração linear dos 17 minutos até 24 horas ou mais. Pelos resultados observados, concluíram que as resinas acrílicas estudadas apresentaram uma contração de polimerização de 6,5 a $7,9 \%$; oitenta por cento da mudança dimensional ocorreu antes dos 17 minutos em temperatura ambiente, e que a alteração da proporção pó/líquido pela adição de mais líquido aumenta significantemente a contração do material.

CHAl et al..$^{09}$, em 1991, fizeram um estudo para avaliar os sistemas adesivos de cinco elastômeros: um polissulfeto, uma silicona de condensação, um poliéter e um polivinilsiloxano com duas densidades (regular e pesado). Para avaliar a força de união dos adesivos, utilizaram blocos de resina acrílica com uma polegada quadrada que apresentavam um gancho fixado em uma de suas faces, e que seria ligado ao dispositivo universal de ensaios de carga. 
Uma placa metálica perfurada foi utilizada para reter mecanicamente o elastômero. A espessura deste material entre a placa metálica e o bloco de resina era de $1 / 8$ de polegada, e o adesivo era aplicado na superfície de ambos. Cada espécime foi submetido a uma força de tração com velocidade de 5 polegadas por minuto. O mesmo teste descrito para resina foi feito com poliestireno (material utilizado em moldeiras de estoque). Foi testado também, o efeito da variação da velocidade de separação das placas sobre a força de união dos adesivos. Nesta etapa, utilizaram a resina acrílica como material de moldeira e a velocidade de separação de 20 polegadas por minuto foi comparada com aquela de 5 polegadas por minuto. Quando foi utilizada a resina acrílica, os resultados mostraram não haver diferença significante entre os sistemas adesivos, exceto para o polivinilsiloxano de massa (pesado), não havendo qualquer sinal de adesão entre este material ao adesivo. Quando a força de união de cada material com a resina acrílica foi comparada com a do poliestireno, o polivinilsiloxano de viscosidade média mostrou estatisticamente maior força de união com este último. O polissulfeto e a silicona de condensação aderiram significantemente melhor à resina do que ao poliestireno, enquanto para o poliéter os resultados foram equivalentes. As duas diferentes velocidades de separação não revelaram qualquer diferença significante sobre a força necessária para separar as placas.

Idealmente, troquéis utilizados para fazer restaurações dentárias deveriam ser réplicas exatas dos dentes preparados. Para atingir este objetivo, o material de impressão e o gesso dental devem ter características compatíveis. Com esta afirmação, PRICE et al. ${ }^{28}$, em 1991, fizeram a 
introdução do estudo onde procuraram avaliar a alteração dimensional absoluta ocorrida em três áreas de troquéis obtidos de 12 combinações entre diferentes elastômeros e gessos. Um troquel que simulava um dente molar preparado para receber uma coroa total foi construído com uma liga metálica comum; o troquel de aspecto polido recebeu pontos de referência (côncavos) nas superfícies circundantes e oclusal, e a distância entre estes pontos podia ser verificada com um microscópio. Moldeiras de resina acrílica (perfuradas) foram produzidas para fornecerem aproximadamente $4 \mathrm{~mm}$ de espaço para o elastômero. Os moldes foram obtidos com três diferentes siliconas de adição de auto-mistura e um poliéter, com seus respectivos adesivos; eram polimerizados por 10 minutos em temperatura de $22 \pm 1^{\circ} \mathrm{C}$, e deixados por 1 hora na mesma temperatura antes de serem preenchidos com um dos três diferentes tipos de gesso utilizados. Com base nos resultados observados, concluíram que: 1) todos os troquéis de gesso eram maiores que o troquel metálico, mas o aumento no tamanho era exíguo; 2) embora diferenças significantes tenham sido observadas entre algumas combinações de elastômero e gesso, a diferença entre os troquéis de gesso esteve sempre dentro do limite de $9 \mu \mathrm{m}$; 3) nenhuma das combinações entre elastômeros e gesso produziu consistentemente o menor ou maior troquel nas três direções medidas (altura, largura ou comprimento).

MARCHESE ${ }^{21}$ (1994) avaliou a precisão dimensional de troquéis de gesso do tipo IV através de dois métodos de medição:um do perfil do troquel, que consistia em medir três diâmetros (oclusal, médio e cervical) em um microscópio comparador, e outro no qual utilizou um microscópio de leitura de 
profundidade para medir a adaptação de uma coroa-padrão sobre os troquéis. O dispositivo de moldagem empregado foi aquele desenvolvido por ARAÚJO; JÖRGENSEN ${ }^{02}$, e os elastômeros testados foram Provil-H, Baysilex e Permlastic, em duas diferentes temperaturas de polimerização. $O$ autor concluiu que: o método de medição direta das dimensões dos diâmetros dos troquéis de gesso é inadequado para avaliar a fidelidade dos mesmos; 2) estatisticamente, o Baysilex e o Provil-H permitiram a obtenção de troquéis significativamente mais fiéis do que o Permlastic; 3) a temperatura de $37^{\circ} \mathrm{C}$ conduziu a piores resultados, com significância estatística, do que a de $23^{\circ} \mathrm{C}$.

DIMASHKIEH; MORGANO ${ }^{13}$, em 1995, descreveram uma técnica na qual a moldagem para cada dente preparado é feita com coroas temporárias pré-fabricadas e sobre estas, uma moldagem com moldeira de estoque (preenchida com o mesmo elastômero usado nos moldes individuais). Obtémse assim um molde de todo o arco, que incorpora moldes precisos de cada dente preparado, inclusive da linha de terminação. Cada coroa temporária deve ser ajustada de modo que a margem gengival se estenda um pouco além da linha já citada. O adesivo aplicado sobre as superfícies interna e externa da coroa provisória deve ser aquele recomendado pelo fabricante do respectivo elastômero. Os autores ressaltam que esta técnica tem muitas vantagens, por ser desnecessário o uso de fios retratores, agentes químicos ou eletrocirurgia para promover o afastamento do tecido gengival. Além disto, a pequena espessura do elastômero no interior do molde ameniza o efeito de sua contração de polimerização, tornando o molde mais preciso. 
Em 1996, BOULTON et al. ${ }^{06}$ investigaram a precisão tanto horizontal como vertical de troquéis de gesso obtidos a partir dos moldes de 3 elastômeros: uma silicona de adição, (Exaflex®), técnica da dupla mistura e do reembasamento da massa com a pasta fluida), um poliéter, (Permadyne®), e um polissulfeto, (Permlastic $\left.{ }^{\circledR}\right)$, utilizando dois tipos de moldeiras: de estoque e padronizadas; estas últimas eram feitas com resina acrílica e reservavam aproximadamente $3,5 \mathrm{~mm}$ de espaço para o elastômero. Os troquéis-padrão simulavam a forma e a dimensão de molares e pré molares preparados para receberem uma prótese fixa. As dimensões dos troquéis e entre os troquéis de gesso resultantes eram avaliadas em 16 pontos com um projetor de perfil. Com a análise dos resultados, concluíram que: impressões feitas com moldeiras padronizadas e com elastômeros, exceto os polissulfetos, irão minimizar as alterações dimensionais dos troquéis de gesso; a utilização de moldeiras de estoque produzirá resultados não confiáveis em relação à distância entre os pilares; clinicamente, as moldeiras de estoque revelaram-se aceitáveis para restaurações unitárias, desde que os polissulfetos sejam evitados; e que para trabalhos de ponte fixa, os resultados mais precisos seriam obtidos com a utilização de moldeiras padronizadas para todos os tipos de materiais.

Segundo CORSO et al. ${ }^{12}$, em 1998, os fatores primários a afetar as alterações dimensionais de moldes são a contração térmica e de polimerização, e também a perda de substâncias voláteis pelos elastômeros. Por considerarem que poucos estudos tiveram como objetivo avaliar o efeito das mudanças térmicas sobre a estabilidade dimensional dos elastômeros, conduziram uma investigação a este respeito utilizando um polivinilsiloxano e 
um poliéter. Cento e quarenta e quatro impressões foram obtidas a partir de um troquel de aço polido semelhante àquele apresentado pela ADA em sua especificação $n^{\circ}$ 19. As moldeiras de resina acrílica promoviam uma espessura uniforme de $3 \mathrm{~mm}$ para o elastômero, sendo que metade recebeu perfurações como forma de prover retenção mecânica para o material. Assim que a moldeira com o material era assentada sobre o troquel, o conjunto era colocado em uma sala com temperatura controlada de $35 \pm 1^{\circ} \mathrm{C}$ para reproduzir a temperatura intra-oral. As medições iniciais foram feitas à temperatura de $35 \pm 1^{\circ} \mathrm{C}$ com um microscópio de resolução de 0,5 $\mu \mathrm{m}$. Os 144 espécimes foram divididos em 12 grupos, com 6 grupos para cada elastômero. Metade das moldagens para ambos materiais foram executadas com moldeiras perfuradas e a outra metade com moldeiras não perfuradas. Cada combinação entre os dois materiais de impressão e os dois tipos de moldeiras foi armazenada por 24 horas em três diferentes temperaturas: 23,40 e $4^{\circ} \mathrm{C}$; em seguida permaneciam por um tempo adicional de 2 horas à temperatura de 23 ${ }^{\circ} \mathrm{C}$, quando era executada uma segunda leitura no tempo de 26 horas. Com base nos resultados observados, as seguintes conclusões foram extraídas: 1) a armazenagem de ambos os elastômeros à temperatura de $4{ }^{\circ} \mathrm{C}$ por 24 horas seguida de permanência em temperatura ambiente resultou em moldes ligeiramente expandidos que compensaram parcialmente a contração de polimerização do malterial; 2) armazenando o poliéter a $40{ }^{\circ} \mathrm{C}$ por 24 horas e então permanecendo em temperatura ambiente, também resultou em moldes ligeiramente expandidos; 3) os efeitos do uso de moldeiras perfuradas ou não, sobre a estabilidade dimensional de moldes obtidos de um troquel sem 
retenção, foram inconsistentes; 4) a média das alterações dimensionais registradas neste estudo variaram de 1 a $18 \mu \mathrm{m}$.

MARCHESE ${ }^{22}$, em 1999, avaliou a fidelidade de troquéis de gesso, utilizando duas técnicas de moldagem: dupla moldagem (com espessura de 1 e $2 \mathrm{~mm}$ para a pasta do elastômero), e casquete (com $1 \mathrm{~mm}$ de espessura para o material). O autor afirmou que qualquer que seja o elastômero eleito, o método mais confiável para se avaliar o seu desempenho em conduzir a modelos de gesso fiéis, parece ser aquele no qual é empregada uma coroa padrão que se adapta com precisão ao troquel apropriado. Foram utilizados cinco elastômeros (Express $₫$, Impregum $F \circledast$, Imprint $₫$, Permlastic $®$ e President $₫$ ); os moldes foram obtidos empregando-se um dispositivo de moldagem idealizado por ARAÚJO E JORGENSEN ${ }^{02}$, e em seguida preenchidos com gesso tipo IV (VelMix®). As avaliações da adaptação da coroa padrão sobre os troquéis foram feitas com um microscópio de medição de profundidade. Foram constatadas diferenças significantes entre as condições estudadas. Os resultados mostraram que a técnica do casquete apresentou melhores resultados para os materiais Impregum F e Imprint, vindos a seguir o Express e o President (ambos com alívio de $2 \mathrm{~mm}$ ) e o Express (alívio de $1 \mathrm{~mm}$ ); o Permlastic e o Express, na técnica do casquete, apresentaram piores resultados que os anteriores, mas semelhantes entre $\mathrm{si}$, sendo o President (casquete) semelhante a este último; o President (alívio de $1 \mathrm{~mm}$ ) foi o que apresentou pior resultado.

Para RAGAIN et al. ${ }^{29}$ (2000), as várias combinações de materiais de impressão com materiais para troquéis têm variados graus de compatibilidade 
dependendo dos parâmetros estimados. A capacidade de umedecimento de um material para troquel sobre um material de impressão pode ser medido pelo ângulo de contato formado pelo primeiro sobre uma amostra plana deste último. A qualidade da superfície pode ser caracterizada pela reprodução dos detalhes e pela dureza desta superfície reagida em contato com o material de impressão. Os autores realizaram este trabalho com o propósito de comparar a reprodução de detalhes, o ângulo de contato e a dureza de superfície entre várias combinações de elastômeros contemporâneos e materiais para troquel sem utilizar qualquer tratamento para melhorar o umedecimento ou reduzir a contaminação biológica da superfície. Elastômeros representativos de quatro classes (polivinilsiloxanos, poliéteres, polissulfetos e hidrocolóides reverssíveis) e três materiais para troquel(gessos do tipo IV, tipo $V$ e tipo IV reforçado com resina) foram utilizados. Para avaliar a reprodução de detalhes de superfície, a largura da linha contínua mais fina e a forma da linha mais grossa observada foram determinadas em amostras obtidas a partir de um troquel padrão semelhante àquele apresentado pela American Dental Association em sua especificação $n^{\circ} 19$; o ângulo de contato formado pelos materiais para troquel sobre o elastômero polimerizado foi medido utilizando-se um goniômetro, e a dureza dos troquéis de gesso foi determinada por valores de dureza Vickers. Pela análise dos resultados observados, os autores concluíram que a reprodução adequada dos detalhes de dentes preparados pode ser obtida com qualquer das combinações entre os materiais estudados; quando se utiliza o polivinilsiloxano ou o poliéter, o gesso do tipo IV reforçado com resina pode produzir troquéis com superfície menos resistente ao risco do que os do tipo IV 
utilizados neste estudo; nenhuma combinação de materiais para troquel e para impressão foi identificada como superior a outras em relação às propriedades de superfície estudadas.

MANTOVANI ${ }^{20}$, em 2001, avaliou a fidelidade dimensional de troquéis de duas marcas comerciais de gessos do tipo IV (Durone ${ }^{\circledR}$ e Vel-Mix ${ }^{\circledR}$ ), obtidos a partir de moldes feitos com uma silicona de condensação (Oranwash $\left.{ }^{\circledR}\right)$, para o qual a moldeira de resina acrílica fornecia uma espessura de 0,2 mm. A condição considerada ideal seria aquela em que os bordos superiores de uma coroa-padrão metálica permanecessem na mesma altura da face oclusal de cada troquel de gesso, assim como ocorria com o troquelpadrão. Concluiu que o gesso Vel-Mix® foi aquele que possibilitou a construção de troquéis morfodimensionalmente mais fiéis nas condições estabelecidas.

GOMES DE SÁ et al. ${ }^{17}$, em 2002, estudaram a fidelidade dimensional de troquéis de um gesso tipo IV (Vel-Mix®), confeccionados a partir de moldes obtidos com uma silicona de condensação (Oranwash ${ }^{\circledR}$ ), nos quais o casquete de resina acrílica utilizado permitia que a camada do material de moldagem, em seu interior, apresentasse espessuras respectivamente de 0,2, 0,5 e 1,0 mm. Uma peça denominada coroa-padrão, quando encaixada adequadamente no troquel-padrão (estrutura original a ser moldada, que simulava um dente preparado para receber uma coroa total), apresentava suas bordas superiores na mesma altura da face oclusa do citado troquel, situação que podia ser comprovada através de um microscópio de leitura de profundidade. A coroapadrão era adaptada em cada troquel de gesso obtido, para avaliação do grau de fidelidade, utilizando-se o microscópio já citado. Foi constatado que todos os 
troquéis de gesso eram maiores do que o troquel-padrão. Estatisticamente, ficou comprovado que as diferentes espessuras do elastômero não conduziram a resultados diferentes entre si.

PIWOWARCZYK et al. ${ }^{27}$, em 2002, afirmaram que entre vários trabalhos nos quais foi avaliada a influência de determinados fatores sobre a fidelidade e estabilidade dimensional de materiais de impressão, apenas os de CLANCY et al. ${ }^{11}$ e de CORSO et al. ${ }^{12}$ lidaram com medições diretamente sobre o molde, sem considerar o material de modelo. Declararam que a exposição exata da precisão dimensional dos materiais de impressão apenas pode ser determinada excluindo-se outras variáveis que exerçam influência. Com a finalidade de examinar a precisão dimensional de elastômeros com apenas uma consistência e de várias classes (6 polivinilsiloxanos e 2 poliéteres), em 2 tempos de vida, os autores executaram ensaios nos quais a distância entre pontos foram verificadas diretamente sobre as impressões. Na realidade as medições eram feitas em pontos localizados no topo de postes cilíndricos que apresentavam a extremidade oposta imersa e retida mecanicamente no elastômero. O dispositivo utilizado consistia de uma base na qual ficavam inseridos os postes de modo que suas extremidades retentivas ficavam livres no interior de um anel que se ajustava à base; o elastômero era inserido no interior deste anel, e assim que estivesse polimerizado, a base era separada do anel expondo então o topo dos postes; antes da aplicação do material de impressão o dispositivo era temperado em água a $35 \pm 1{ }^{\circ} \mathrm{C}$. Na discussão dos resultados observados, os autores lembraram que a deformação dos materiais de impressão foi excluída pela utilização de uma moldeira (anel) rígida e 
resistente à torção, e pela remoção da moldeira em sentido perfeitamente vertical com uma força predefinida. Concluíram que os oito materiais investigados demonstraram precisão dimensional muito alta sob as condições experimentais utilizadas, com diferenças muito pequenas entre eles; e que não houve alterações significativas nas dimensões dos moldes entre os dois tempos de vida estudados. Lembraram, ao final, que a exposição das medidas da recuperação elástica do material de impressão estavam fora da abrangência do estudo. 
Proposição 


\section{Proposição.}

No presente trabalho, o objetivo foi avaliar a fidelidade morfo-dimensional de troquéis de gesso tipo IV, obtidos a partir de moldes de um único elastômero, utilizando-se duas diferentes técnicas de moldagem (com casquete ou com moldeira de estoque), assim compondo-se os quatro seguintes grupos de estudo, sendo que o aquecimento do molde não foi efetuado apenas no primeiro deles:

1- do casquete de resina, sem contato com a porção cervical da estrutura a ser moldada; 2- do casquete, também sem o referido contato ; 3- novamente do casquete, agora com contato e 4-. da moldeira de estoque. 
Materiais e método 


\section{Materiais e método.}

Neste estudo, todos os procedimentos de moldagem, de obtenção de modelos e de leitura dos resultados foram executados em ambiente com controle de temperatura $\left(23 \pm 1^{\circ} \mathrm{C}\right)$ e de umidade relativa do ar $(50+/-5 \%)$.

As ilustrações deste texto encontram-se agrupadas num conjunto de páginas locadas ao final do presente capítulo.

A estrutura original moldada, cujo esquema encontra-se na figura 1 (inclusive onde são encontradas suas dimensões), era confeccionada em aço inoxidável e consistia num troquel-padrão que simulava um dente preparado para receber uma cora total, inclusive apresentando uma região cervical retentiva.

O citado troquel-padrão estava preso num dispositivo de moldagem (mostrado a seguir na figura 2) que possuía duas plataformas, uma inferior denominada base (B), na qual podia ser fixada uma moldeira, e outra superior denominada braço ou parte móvel (PM). Em cada extremidade da base, encontrava-se uma haste cilíndrica vertical (HV); nestas podiam ser encaixados os orifícios existentes nas extremidades do braço, de tal forma que este último podia ser deslocado em toda a extensão das hastes. Na parte intermediária do braço, encontrava-se o já citado troquel-padrão $(T)$, fixado através de um parafuso próprio (PFT) e de um cilindro auxiliar (CAFT), juntamente com um anel metálico (AE) de $3 \mathrm{~mm}$ de espessura, o qual promovia o estabelecimento da altura da região retentiva do troquel-padrão em $1 \mathrm{~mm}$. Numa das hastes existia um anel (AMA), o qual também possuía um parafuso próprio de imobilização com a função de manter qualquer altura estabelecida para a parte móvel. Na citada figura, ainda pode ser observada esquematicamente a 
existência de uma moldeira qualquer (M), a qual poderia ser imobilizada em posições adequadas (usando-se plataformas constituídas por materiais variados), através de um parafuso fixador (PFM); um outro cilindro metálico, denominado centralizador da moldeira (CC) faz parte do presente dispositivo mas não foi utilizado no presente trabalho.

No dispositivo citado ainda existia um anel denominado coroa-padrão (cujo esquema não se encontra na figura 2), igualmente confeccionado em aço inoxidável, cuja luz tronco-cônica apresentava dimensões tais que ele se encaixava com justeza no troquel-padrão; quando este estivesse com a face "oclusal" voltada para cima, o plano desta sua face encontrar-se-ia na mesma altura do plano oclusal da coroapadrão. Esta situação podia ser verificada com o uso de um microscópio de profundidade (Carl Zeiss, da Alemanha Ocidental, com aumento linear original de 128 vezes), quando a concavidade existente na face oclusal da coroa-padrão estivesse radialmente alinhada com a outra marca semelhante, existente na face oclusal do troquel-padrão, próxima à sua borda e denominada como das 12 horas, por analogia a um relógio de ponteiros; tal situação de coincidência é ilustrada pela figura 3.

\section{1- Confecção e fixação das moldeiras.}

Um primeiro troquel auxiliar foi confeccionado em gesso Vel-Mix® (Kerr Mfg. Co., EUA), a partir de um molde obtido com a mesma técnica de moldagem com casquete que será posteriormente descrita. A partir deste, pelo processo de 
fundições tradicionalmente usado em Odontologia, foi confeccionado um casquete de níquel-crômio com espessura uniforme de 0,2 mm, que aqui será denominado espaçador. Com o casquete espaçador adaptado sobre o troquel auxiliar (na condição ilustrada pela figura 4), aplicava-se sobre ambos uma fina camada de isolante (cera Hoechst V, tipo P 6456, fabricada na Alemanha, dissolvida a 10\% em benzina), para que sobre eles fosse confeccionado, com a técnica do pincel, cada um dos trinta casquetes em resina acrílica Duralay ${ }^{\circledR}$, fabricada por Reliance Dental Mfg. Co., dos EUA) Assim confeccionados, cada casquete utilizado na fase de moldagem do presente estudo tinha no seu interior um espaço uniforme (da mesma espessura do casquete de níquel-crômio) reservado para o material de moldagem, como pode ser visto na figura 5.

Para fixar os casquetes de resina no dispositivo de moldagem, foram confeccionadas algumas placas de aço perfuradas, com duas pequenas hastes.

Um casquete de moldagem (com o casquete espaçador posicionado em seu interior) era então adequadamente encaixado no troquel-padrão. Uma pequena porção de godiva plastificada era então aplicada sobre a placa perfurada, já fixada na base do dispositivo de moldagem; o braço deste era encaixado nas hastes e abaixado até que o casquete acrílico viesse a ficar preso na godiva, como mostrado na figura 6; desta forma, o casquete de resina ficava centralizado em relação ao troquel-padrão, em função do casquete metálico. Depois de a godiva esfriar, o braço do dispositivo era levantado, como pode ser visto na figura 7, deixando o casquete fixado na placa perfurada e centralizado da forma explicada. Em seguida, o braço era removido do dispositivo e, do interior do casquete de resina era removido o casquete espaçador, operação ilustrada pela figura 8. 
Num primeiro grupo de 20 casquetes, não existia contato direto da resina acrílica com o troquel, na região cervical, como foi explicado. No grupo restante, constituído pelos demais 10 casquetes, a porção cervical de cada um deles apresentaria o tal contato. Estas duas situações dos casquetes (sem e com contato cervical) estão ilustradas pela figura 9.

Para criar o referido contato nestes 10 últimos casquetes, era necessário primeiro fixá-los na placa perfurada, da maneira já descrita para os demais; um segundo troquel auxiliar, cuja região retentiva havia sido bloqueada com o mesmo gesso já citado, era fixado no braço do dispositivo de moldagem, no lugar do troquelpadrão; para tanto, foi confeccionado um suporte de resina acrílica comum, o qual possibilitava que este segundo troquel auxiliar viesse a ficar numa posição igual, tanto quanto possível, à anteriormente ocupada por aquele. Após este troquel de gesso ser isolado com o mesmo produto já citado, uma pequena porção da resina Duralay era aplicada em toda sua região cervical. Em seguida, o braço do dispositivo era adaptado à base e abaixado, até que o troquel viesse a ficar plenamente inserido no casquete de resina, de cujo interior já havia sido removido o espaçador. Nesta operação, o troquel auxiliar, substituindo o troquel-padrão, permitia que este não fosse danificado principalmente pela resina acrílica utilizada para criar o contato cervical.

Assim que a resina estivesse polimerizada, o braço do dispositivo era removido, trazendo consigo o troquel auxiliar; os pequenos excessos de resina eram então aparados com uma lâmina de bisturi. Nesta condição, no futuro ato de moldar, o contato da resina com o troquel-padrão aconteceria cervicalmente, numa extensão de aproximadamente $1,5 \mathrm{~mm}$ de altura. 
Para a técnica da moldeira de estoque, foram confeccionadas, a partir de placas de aço perfuradas, três moldeiras semelhantes, nas quais tanto o diâmetro como a altura, internos, eram de $16 \mathrm{~mm}$, o que possibilitava que o espaço futuramente ocupado pelo material de moldagem fosse de $3,5 \mathrm{~mm}$, na região do maior diâmetro do troquel-padrão.

A centralização da moldeira de estoque era executada com o auxílio de um cilindro confeccionado com o próprio elastômero analisado no presente trabalho, identificado à frente, preparado de maneira que se encaixasse com justeza tanto no troquel-padrão como no interior da moldeira; após tal centralização, esta era então fixada na base, pelo respectivo parafuso.

\section{2- Obtenção dos moldes.}

O elastômero utilizado neste trabalho foi o Impregum $\mathrm{F}^{\circledR}$ (3M ESPE, Seefeld, Alemanha), do lote de número 22012, com data de fabricação AGO/2001 e validade de três anos a partir da data de fabricação; estas informações estão contidas na embalagem do produto, o qual foi aqui utilizado dentro do prazo de validade.

Antes de cada moldagem, o troquel-padrão era limpo com uma gaze embebida numa solução composta por partes iguais de álcool absoluto e éter sulfúrico, recebendo em seguida, com pincel comum, a aplicação de estearato de cálcio, até compor-se uma camada uniforme e o mais fina possível, cuja função era evitar a adesão do elastômero ao metal do troquel. Nesta ocasião, o troquel-padrão estava pronto para ser moldado. 
No interior, na borda e numa extensão de aproximadamente $2 \mathrm{~mm}$ da superfície externa dos casquetes acrílicos era aplicado o adesivo apropriado, fornecido com o elastômero, cuja secagem era esperada ocorrer espontaneamente por 5 minutos. O aspecto de um casquete com o adesivo nele aplicado pode ser observado na figura 10.

Já para as moldeiras perfuradas, nenhum adesivo foi usado pois a retenção do elastômero em seu interior era mecânica, pelo extravasamento do material através dos furos.

Pela fotografia 11, pode-se ter uma idéia do espaço disponível para o elastômero, no interior de uma moldeira perfurada e de um casquete de resina.

Sobre uma folha de papel fornecida pelo fabricante do elastômero, colocada sobre o prato de uma balança de precisão (modelo D7470, Sauter, fabricada na Alemanha Ocidental), eram inicialmente pesadas porções de pasta base e catalisadora, na proporção de $7 / 1$, recomendada pelo fabricante; uma destas ocasiões está ilustrada na figura 12. Para a moldagem com casquete, os valores eram respectivamente $1,4 \mathrm{~g}$ e $0,2 \mathrm{~g}$, enquanto, para a moldeira perfurada, tais valores eram $3,5 \mathrm{~g}$ e $0,5 \mathrm{~g}$.

Sobre o mesmo papel, efetuava-se a mistura das pastas com uma espátula $\mathrm{n}^{\circ}$ 24, por 45 segundos. A pasta homogênea resultante era inserida no interior de uma seringa plástica, com capacidade para $5 \mathrm{ml}$, e inicialmente utilizada para preenchimento completo da moldeira ou do casquete, o restante do material era aplicado na região cervical do troquel-padrão. Imediatamente, o braço do dispositivo era encaixado nas hastes de sua base, sendo abaixado, para que assim fosse efetuada a moldagem, momento no qual o braço era fixado, através de seu parafuso 
próprio; para esta tarefa, era empregado um tempo de 45 segundos; nesta ocasião, o elastômero extravasava da moldeira perfurada ou do casquete, como é mostrado respectivamente pelas figuras 13 e 14 .

Imediatamente após ter ocorrido o citado extravasamento do elastômero, o conjunto formado pelo dispositivo de moldagem com a moldeira ou o casquete nele fixado era imerso em água mantida a $37 \pm 1^{\circ} \mathrm{C}$, exceto para o grupo de casquete sem aquecimento, nos quais o referido conjunto permanecia sobre a bancada, nas já citadas condições ambientais. Em todos os grupos, o tempo aguardado para a polimerização do elastômero era de 10 minutos, contados a partir do momento da fixação do braço, quando então o troquel-padrão era removido do interior do respectivo molde.

As figuras 15 e 16 mostram o aspecto de moldes respectivamente obtidos com casquete e com moldeira perfurada.

\section{3- Obtenção dos modelos.}

Para que cada troquel viesse a ter uma base com altura suficiente para facilitar o seu manuseio, em torno de cada molde, no caso dos casquetes, era utilizada fita crepe, para construir um dique, após se eliminar o material extravasado; nas moldeiras perfuradas este procedimento era desnecessário pois o material extravasado já funcionava como uma espécie de dique.

Cinco minutos depois do troquel-padrão ser removido do molde, era confeccionado o respectivo troquel de gesso Vel-Mix®; assim, $5 \mathrm{~g}$ de pó do gesso 
(quantidade anteriormente pesada na balança já citada) eram misturados manualmente com $1 \mathrm{ml}$ de água deionizada (anteriormente medido com pipeta), sobre um vibrador comum, por 1 minuto. A massa fluida resultante era imediatamente vertida no interior do molde (com o auxílio do mesmo vibrador), até seu preenchimento completo e formação da base. Era aguardado o tempo de uma hora (contado do início da mistura), para efetuar-se a desmoldagem do troquel de gesso. O aspecto do troquel assim obtido era examinado com lupa de pequeno aumento, para detecção de eventuais defeitos que motivassem seu descarte; nódulos pequenos (obviamente assim considerados por julgamento subjetivo) eram cuidadosamente removidos com lâmina de bisturi. Sete dias depois de sua confecção, o troquel era então nivelado, pela sua face oclusal, como está ilustrado pela figura 17, com auxílio de um verticulador comum, em cuja base aquele ficava preso com massa de modelagem, como pode ser constatado na figura 18; tal nivelamento era necessário, para que fosse possível efetuar a análise da adaptação, empregando-se a coroa-padrão e o microscópio de profundidade já referidos, numa condição ilustrada pela figura 19.

Em cada troquel de gesso, para cada uma das suas regiões (12, 3, 6 e 9 horas), a diferença de altura (expressa em micrometros) entre sua face oclusal e a borda superior da coroa-padrão foi verificada por três vezes. O valor da média aritmética destas 12 leituras era considerado como expressivo do grau individual de adaptação (ou seja, de fidelidade) do troquel.

Podia-se facilmente observar, mesmo à vista desarmada, que a borda superior da coroa-padrão (quando esta se encontrasse adaptada em alguns dos troquéis de gesso) encontrava-se praticamente na mesma altura da face oclusal 
destes, como está ilustrado pela figura 20; em outros casos, ficava nítido que aquela se encontrava mais alta do que a tal face, como ilustrado pela figura 21.

Para facilitar citações subseqüentes, os grupos das condições aqui estabelecidas foram identificados por siglas, da forma seguinte:

1) Casquete, sem toque, sem aquecimento Cstsa.

2) Casquete, sem toque, com aquecimento Cstca.

3) Casquete, com toque, com aquecimento Cctca.

4) Moldeira perfurada, com aquecimento Mca.

Os dados individuais detectados nos troquéis foram posteriormente submetidos ao tratamento estatístico, o qual constou inicialmente de uma análise de variância, seguida de um teste de Tuckey, cujos resultados podem ser encontrados no capítulo seguinte. 
Ilustrações do texto do presente capítulo.

As legendas das ilustrações aqui encontradas estão escritas de modo resumido, visto que explicações mais detalhadas são encontradas no respectivo texto.

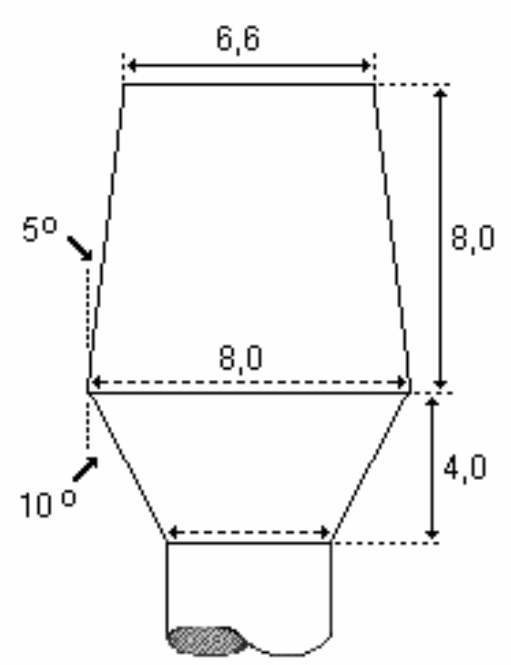

Figura 1. Esquema da estrutura original moldada, com suas dimensões expressas em milímetros e seus ângulos em graus.

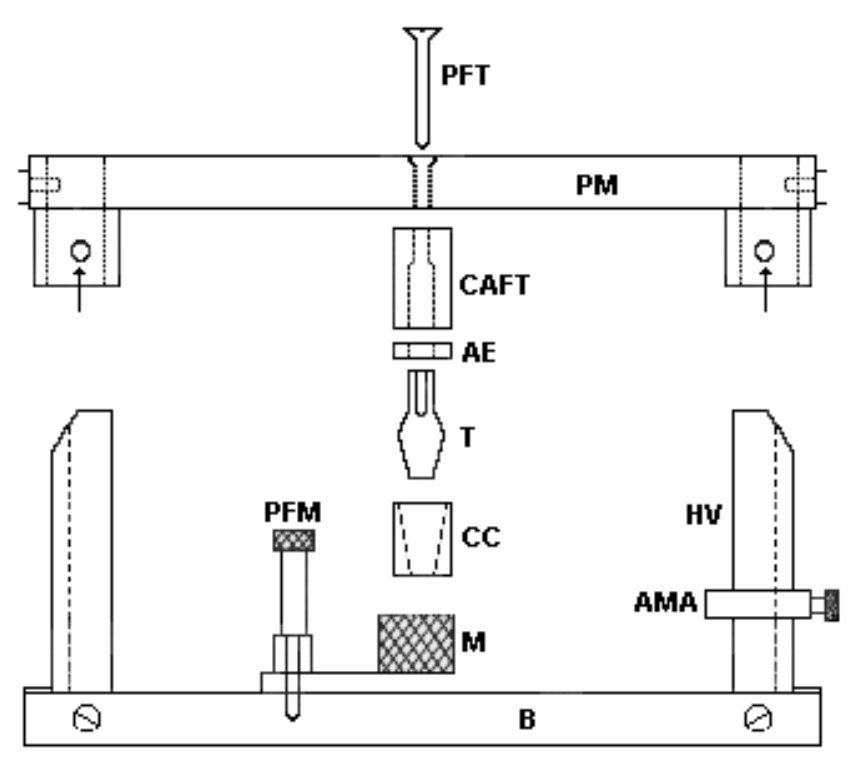

Figura 2. Esquema dispositivo de moldagem utilizado, cujas partes componentes são identificadas e detalhadas no texto. (Modificado do original de Marchese $^{22}$.) 


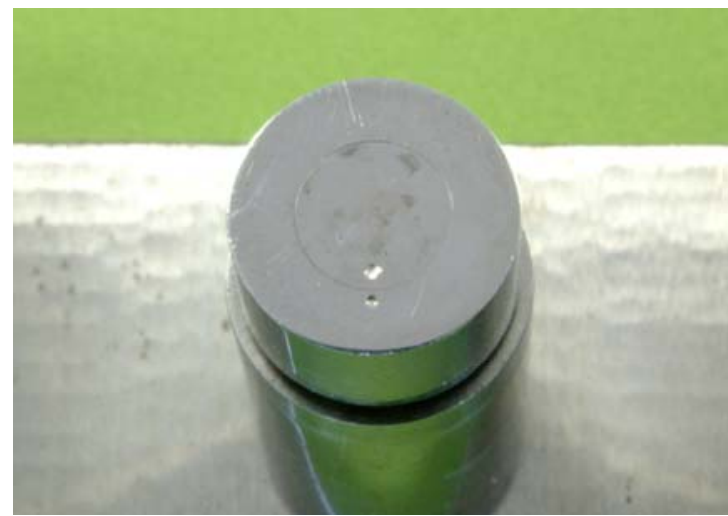

Figura 3 - Coroa-padrão adaptada no troquelpadrão.

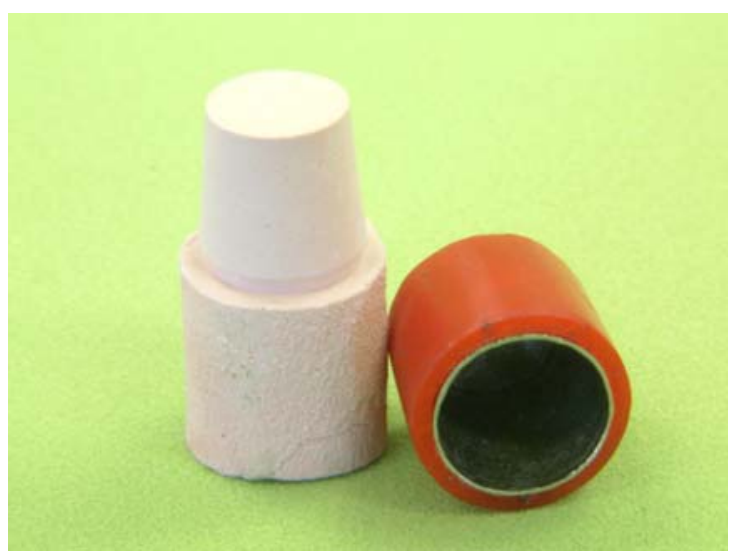

Figura.6.-. Casquete de resina sendo fixado na placa perfurada.

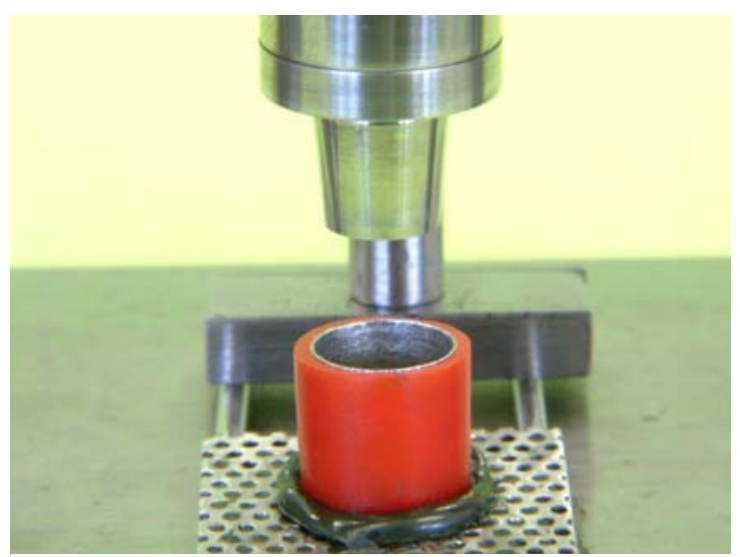

Figura 7 - Um casquete de resina já centralizado.

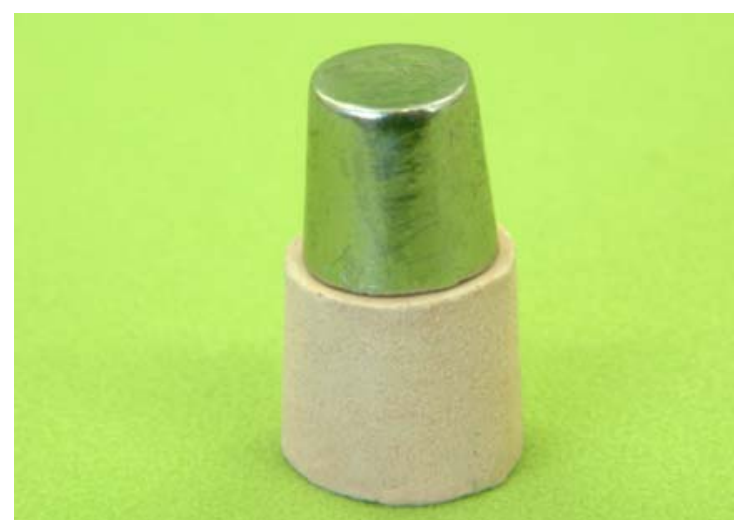

Figura 4 - Troquel auxiliar com o casquete espaçador.

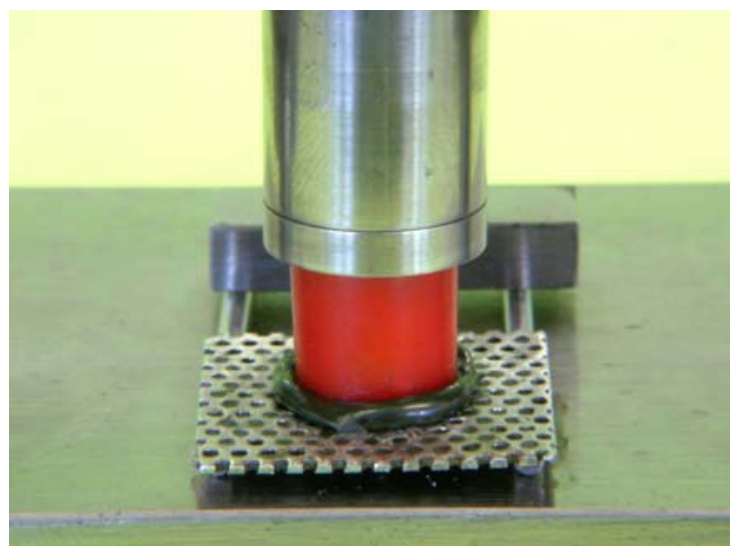

Figura 5 - Troquel auxiliar e um casquete de resina contendo o casquete espaçador.

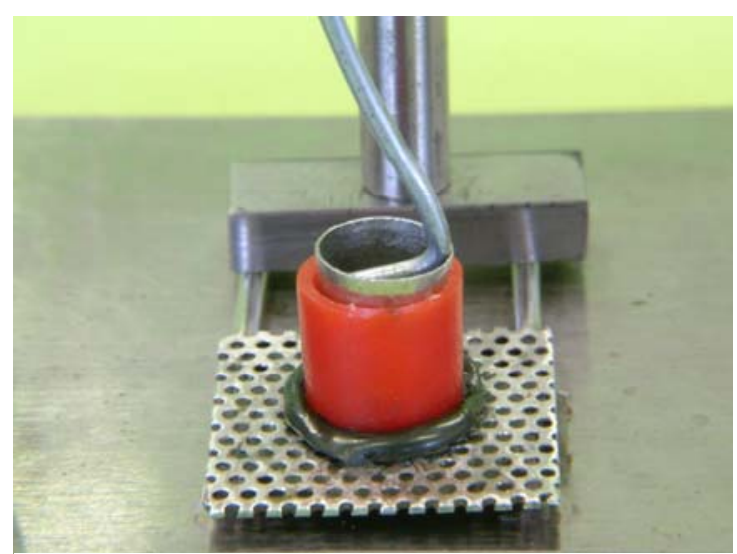

Figura 8 - Casquete metálico sendo removido do interior do casquete de resina. 

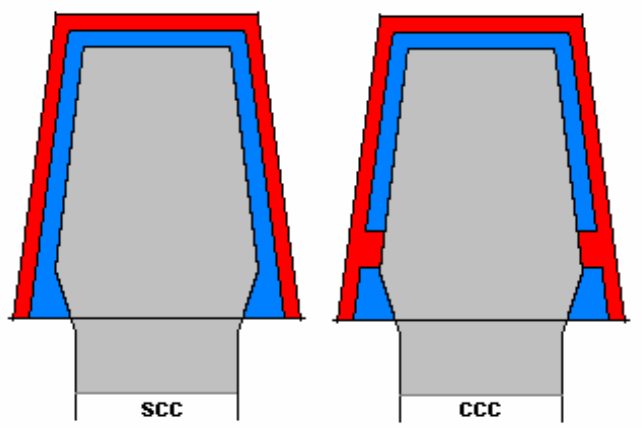

Figura 9 Casquetes sem e com contato cervical

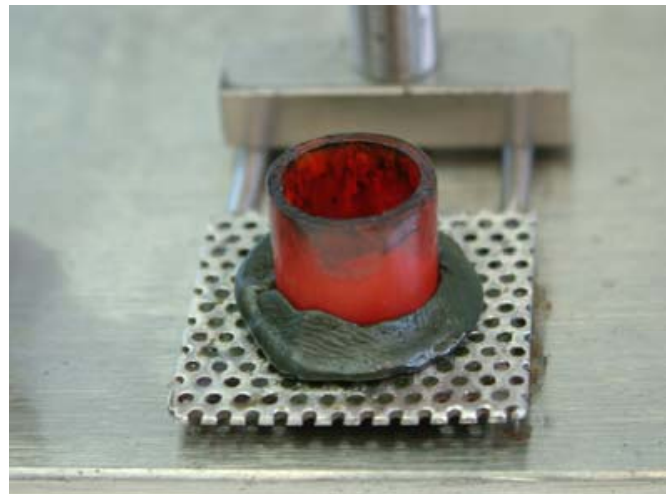

Figura 10 - Aspecto de um casquete com o adesivo nele aplicado

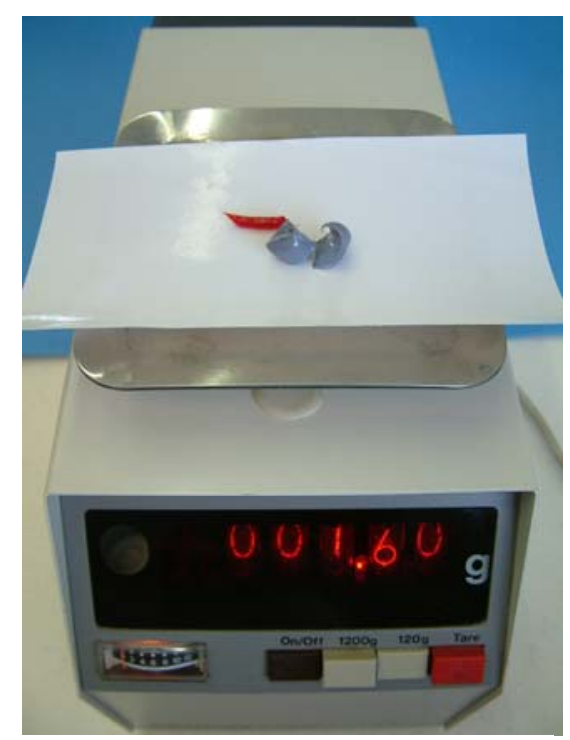

Figura 12 Balança de precisão

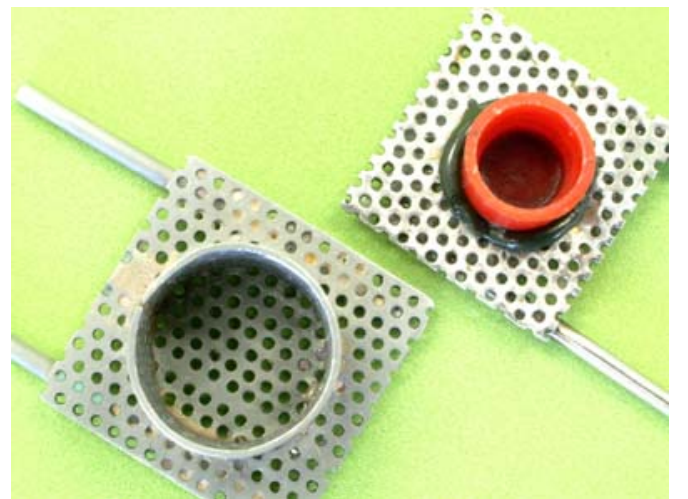

Figura 11 - Espaço disponível para o elastômero, no interior de uma moldeira perfurada e de um casquete de resina.
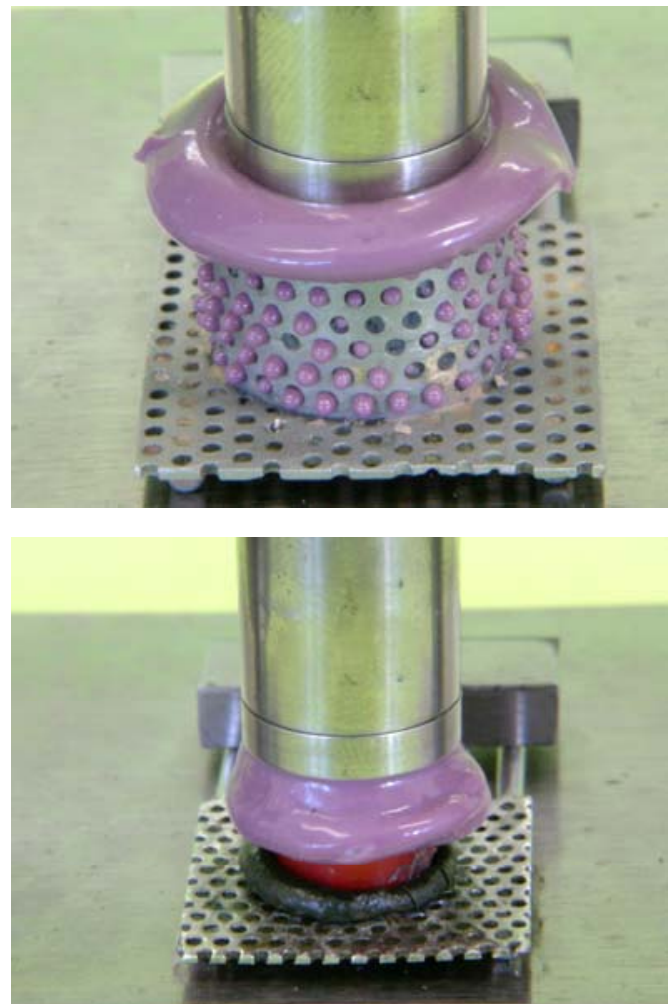

Figuras 13 e 14 - Elastômero extravasava da moldeira perfurada ou do casquete 

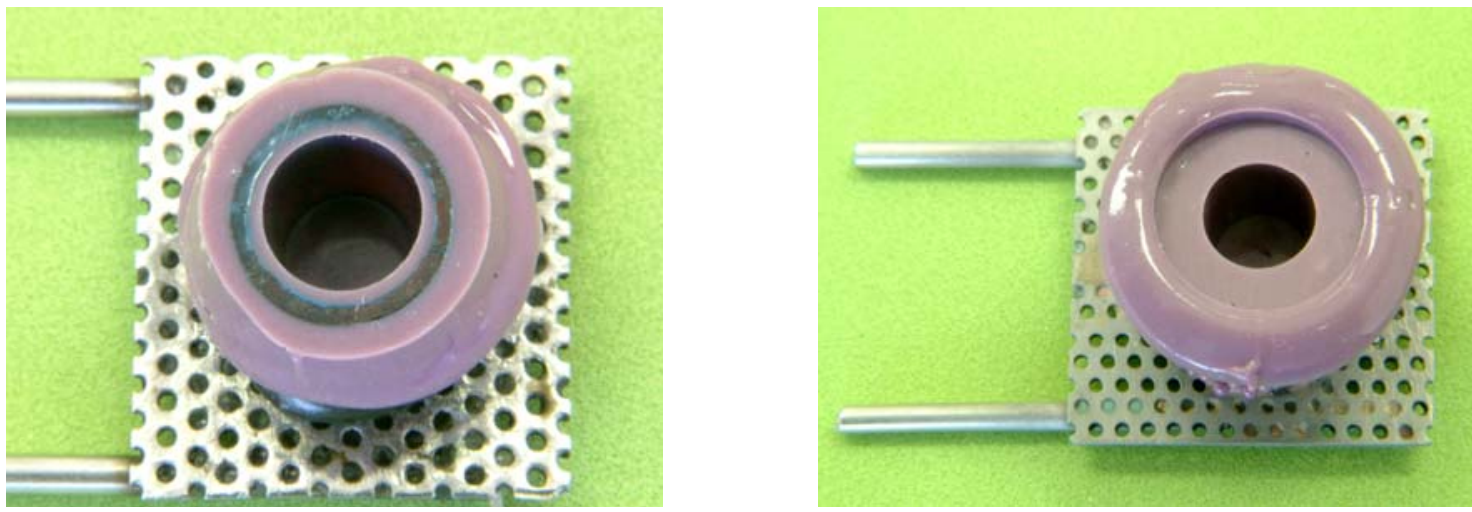

Figuras 15 e 16 - Aspecto de moldes respectivamente obtidos com casquete e com moldeira perfurada.
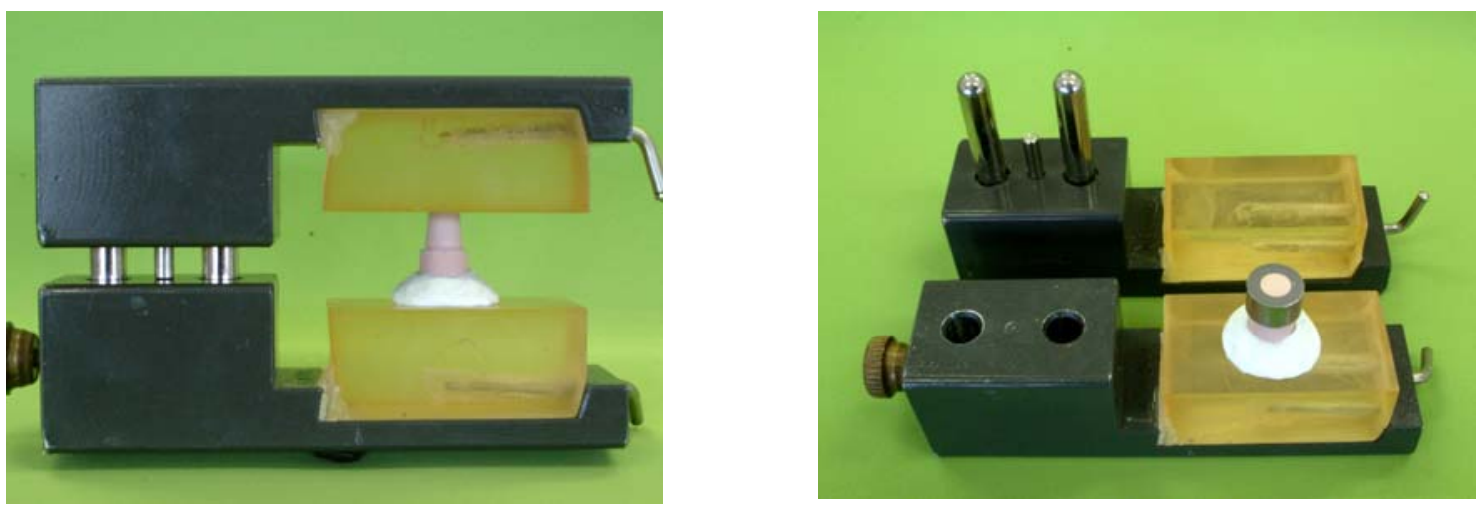

Figura 17 - Troquel nivelado, pela sua face oclusal

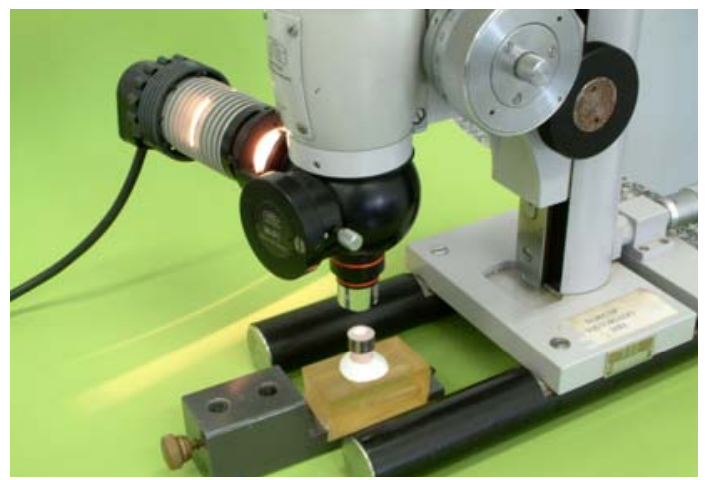

Figura 19 - Microscópio de profundidade

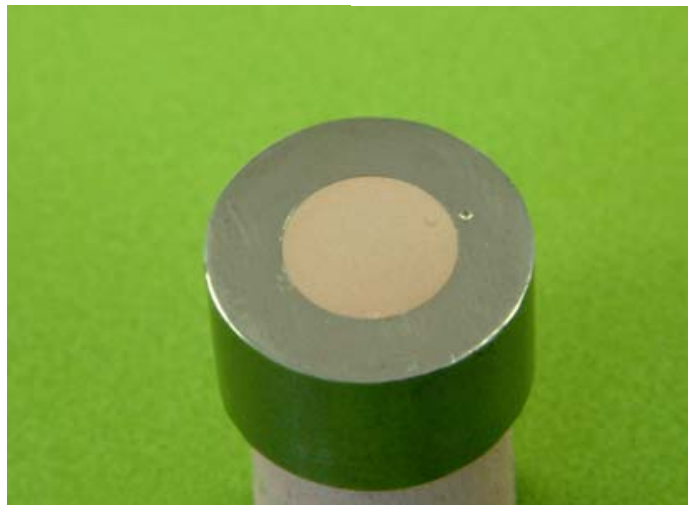

Figura 20

Borda superior da coroa-padrão praticamente na mesma altura da face oclusal do troquel.

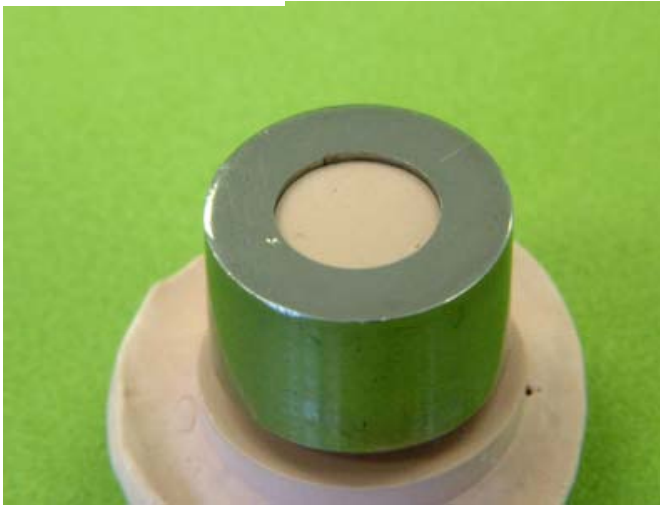

Figura 21

Borda superior da coroa-padrão mais alta do que a face oclusal do troquel. 
Resultados 


\section{5- Resultados.}

Os valores individuais (expressos em micrometros) do nível de adaptação da coroa-padrão a cada troquel de gesso, para cada uma das quatro condições estudadas, estas com suas médias e seus desvios-padrão, são apresentados na tabela 1.

Tabela 1 - Valores individuais (em micrometros) da adaptação da coroa-padrão em cada troquel de gesso, para cada uma das quatro condições estudadas, estas com suas médias (m) e seus desvios-padrão (dp).

\begin{tabular}{c|r|r|r|r}
\hline Troquel & Cstsa & Cstca & Cctca & Mca \\
\hline 1 & 32,66 & 44,74 & 25,33 & 286,74 \\
\hline 2 & 77,83 & $-34,08$ & 126,33 & 453,33 \\
\hline 3 & 30,32 & $-38,74$ & 146,33 & 362,24 \\
\hline 4 & 64,83 & $-20,08$ & 42,58 & 353,74 \\
\hline 5 & 171,07 & 20,91 & 10,91 & 329,58 \\
\hline 6 & 217,49 & $-21,24$ & 45,41 & 427,99 \\
\hline 7 & 36,91 & 60,49 & 213,99 & 468,33 \\
\hline 8 & 312,07 & $-32,58$ & 145,49 & 411,99 \\
\hline 9 & 59,83 & $-2,58$ & 67,33 & 409,66 \\
\hline 10 & 20,83 & 23,41 & 29,99 & 473,41 \\
\hline $\mathbf{m}$ & $\mathbf{1 0 2 , 3 8}$ & $\mathbf{0 , 0 3}$ & $\mathbf{8 5 , 3 7}$ & $\mathbf{3 9 7 , 7 0}$ \\
\hline $\mathbf{d p}$ & $\mathbf{9 8 , 1 8}$ & $\mathbf{3 5 , 3 2}$ & $\mathbf{6 7 , 9 2}$ & $\mathbf{6 2 , 5 6}$ \\
\hline
\end{tabular}

Pode ser observado que todas as médias sempre se apresentaram com caráter positivo, mesmo no caso do grupo Cstca, no qual existiram alguns valores individuais negativos.

Com os dados desta tabela, elaborou-se o gráfico 1, que facilita a percepção global dos resultados obtidos. 


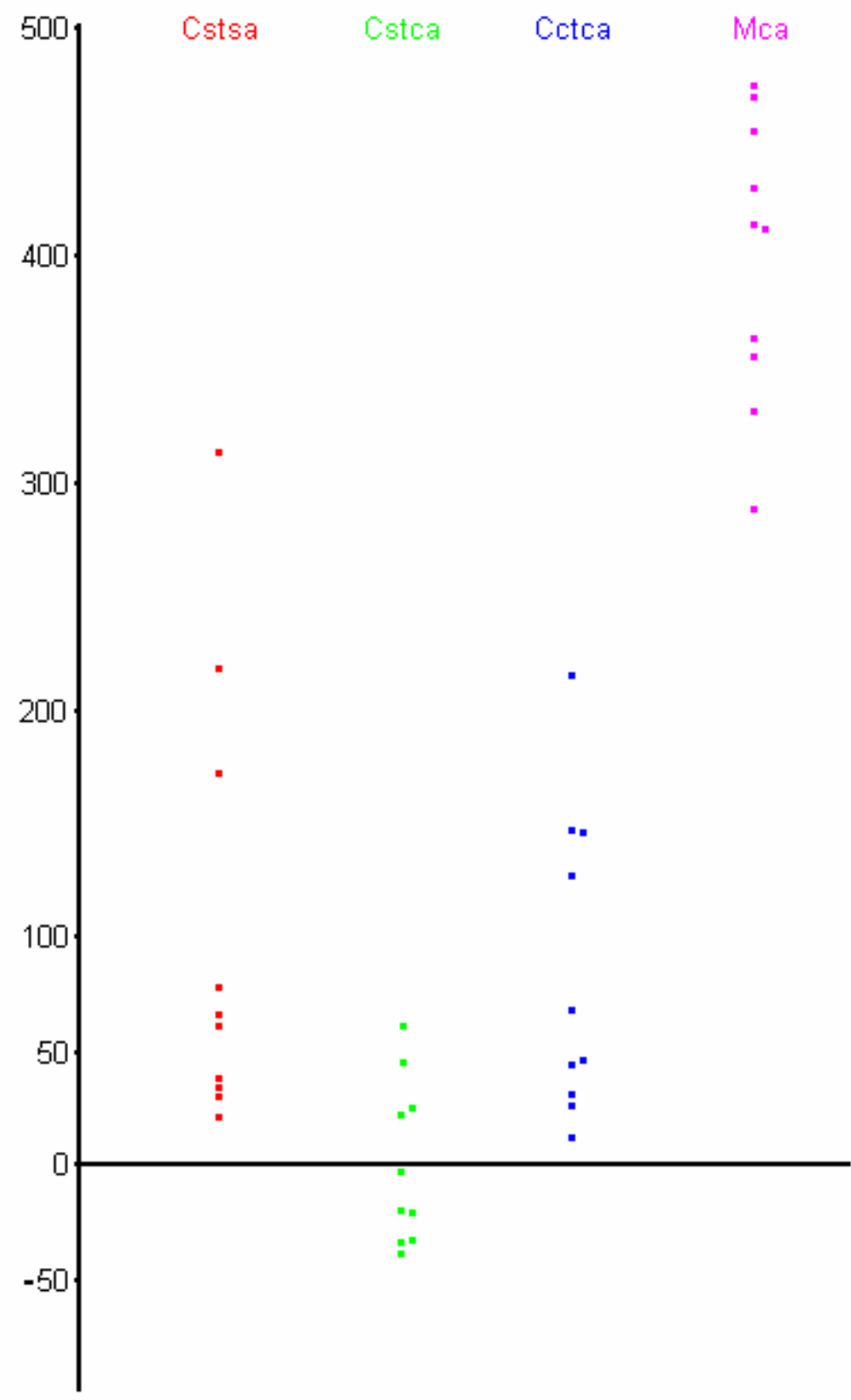

Gráfico 1 - Ilustrativo da tabela 1, com valores expressos em micrometros. 
Aplicada aos dados da tabela 1, uma análise de variância, a 1 critério de classificação, modelo fixo, apresentou um $\mathrm{f}_{\mathrm{obs}}=61,98$, mostrando que existiam diferenças significantes entre as condições estudadas, a um nível de significância de 0,01 \%.

Conseqüentemente, foi utilizado um teste de Tukey, ao nível de significância de 5\%, que demonstrou que o melhor comportamento ocorreu para o grupo Cstca, vindo a seguir os grupos Cctca e Cstsa (com comportamento semelhante), seguidos pelo grupo Mca, o com pior desempenho. 
Discussão 


\section{Discussão.}

O dispositivo de moldagem utilizado neste trabalho é semelhante àqueles empregados por ARAÚJO; JÖRGENSEN ${ }^{02,03}$, GOMES DE SÁ ${ }^{17}$, MANTOVANI ${ }^{20}$ e MARCHESE ${ }^{21,22}$. Dadas suas características, obviamente não pode ser utilizado para simular casos de peças que não sejam coroas totais unitárias; pode ser notado que as alterações dimensionais detectadas diretamente nos troquéis obtidos, através da coroa-padrão, refletem indiretamente as alterações ocorridas com o elastômero, durante a polimerização.

Um outro tipo de método muito utilizado para se avaliar o desempenho dos materiais de impressão é aquele no qual a distância entre pontos, presentes em uma ou mais superfícies da estrutura copiada, é medida linearmente e comparada com aquela reproduzida no molde ou no troquel obtido a partir deste.

Embora os dados observados através deste segundo tipo de método possam fornecer informações valiosas, no presente trabalho optou-se pelo método apresentado pois se julgou ser este o mais adequado para se alcançar o objetivo almejado. Reconhece-se porém que, por meio deste método, não é possível qualificar, com precisão, as distorções presentes no troquel, mas apenas quantificálas, o que vale dizer que, como as alterações dimensionais de tais troquéis não ocorrem igualmente em todas as direções, o nível de adaptação da coroa-padrão é expressivo apenas da magnitude destas distorções, não se podendo inferir de que forma exatamente elas ocorreram. 
É importante também ressalvar que resultados obtidos com o método aqui empregado não podem ser comparados àqueles verificados com métodos nos quais tenham sido utilizadas peças fundidas obtidas a partir dos troquéis resultantes, pois nestes últimos o agente que servirá como parâmetro de medição (isto é, a peça fundida) é ajustado à réplica, para então ser provado sobre o troquel que foi moldado (troquel-padrão); esta seqüência de procedimentos simula a condição real encontrada na prática clínica. Já, no método aqui utilizado, o processo é inverso àquele, pois a coroa-padrão (agente que servirá como parâmetro de verificação) é ajustado ao troquel-padrão, para então ser provado sobre a réplica.

Pela progressão de sua polimerização, os elastômeros se contraem no interior de moldes como aqueles aqui utilizados; como estão unidos (por adesivos ou por retenções mecânicas) às paredes da moldeira, supõe-se que o espaço criado no interior destes moldes aumente, em relação àquele ocupado pelo troquel-padrão. De acordo com este raciocínio, acredita-se aqui que, para variadas espessuras da camada do material de impressão presente no interior do molde, haverá proporcionalidade do nível de distorção, ou seja, quanto maior a espessura de tal camada, maior será a distorção.

Ao analisar inicialmente apenas os valores referentes aos grupos com aquecimento, pode-se observar que a condição Cstca apresentou-se como a mais precisa dimensionalmente, enquanto as condições Cctca e Mca produziram troquéis significativamente distorcidos.

Além de possuir uma espessura muito pequena do elastômero, o grupo Cstca é aquele que apresenta o volume mais homogêneo de material no interior da moldeira, fato que pode explicar a excelente precisão desta técnica de moldagem. 
Em oposição, o grupo que apresentou os piores resultados de adaptação foi justamente o da Mca, onde o volume do elastômero é muito maior do que aquele do Cstca.

No caso daquele grupo de casquetes que contatavam o troquel-padrão na região cervical (Cctca), a desadaptação da coroa-padrão pode ter sido causada por irregularidades presentes na superfície da região contatada (o que nem sempre era facilmente detectável, a olho nu, mas sim sob um pequeno aumento), onde, durante a moldagem, o material que entrava em contato com o troquel-padrão provavelmente era já o adesivo aplicado sobre a resina acrílica, e não o elastômero.

Já para o grupo do casquete que não sofreu aquecimento e nem contato (Cstsa), e comparando-o apenas com o outro grupo do casquete, no qual também não houve contato mas houve aquecimento (Cstca), pode-se supor que a contração do elastômero no interior do molde não foi compensada pela contração térmica que ocorreria (inclusive na moldeira), quando o molde é transferido da temperatura de 37 ${ }^{\circ} \mathrm{C}$ para $23^{\circ} \mathrm{C}$. Assim, para o método aqui aplicado, quando o molde é obtido a uma temperatura mais alta, a dimensão do troquel-padrão registrada no molde é maior do que aquela na qual é verificada a desadaptação; a contração do elastômero que acarretaria o aumento do troquel de gesso é anulada (parcialmente) pela diminuição do tamanho deste molde, quando este tiver esfriado. 
Conclusões 


\section{Conclusões.}

Com base nos resultados encontrados nas condições do presente trabalho, quanto à fidelidade morfo-dimensional dos troquéis de gesso obtidos, após o tratamento estatístico dos resultados, foi possível concluir que:

1 - o pior desempenho ocorreu com a moldeira perfurada, com um desajuste médio da ordem de 397, 70 micrometros.

2 - o casquete com toque e com aquecimento (desajuste médio de 85,37 micrometros) apresentou desempenho semelhante ao do casquete sem toque e sem aquecimento (desajuste médio de 102,38 micrometros).

3 - o melhor desempenho ocorreu com o casquete sem toque e com aquecimento, com um desajuste médio de 0, 03 micrometros. 
Referências bibliográficas 


\section{Referências bibliográficas.}

01. AMERICAN DENTAL ASSOCIATION. Council on Dental Materials and Devices. Specification $n^{0}$. 19 for non-aqueous elastomeric dental impression materials. J. Amer. Dent. Ass., v. 94, n. 4, p.733-41, Apr. 1977.

02. ARAÚJO, P. A. JÖRGENSEN, K. D. Effect of material bulk and undercuts on the accuracy of impression materials. J. prosth. Dent., v.54, n.6, p.79194, Dec. 1985.

03. ARAÚJO, P. A.; JÖRGENSEN, K. D. Improved accuracy by reheating addition-reaction silicone impressions. J. prosth. Dent., v.55, n.1, p.11-12, Jan. 1986.

04. BELL, J. W.; von FRAUNHOFER, J.A. The handling of elastomeric impression materials: a review. J. Dent., v.3, n.5, p.229-37, 1975.

05. BOMBERG, T. J. et al. Consideration for adhesion of impression materials to impression trays. J. prosth. Dent., v.60, n.6, p.681-84, Dec. 1988.

06. BOULTON, J. L. et al. A laboratory study of dimensional changes for three elastomeric impression materials using custom and stock trays. Aust. Dent. J., v.41, n.6, p.398-404, 1996.

07. BRADEN, M.; CAUSTON, B.; CLARKE, R. L. A polyether impression rubber. J. Dent. Res., v.51, n.4, p.889-96, Aug. 1972.

08. CANNISTRACI, A. J. A new approach to impression taking for crown and bridge. Dent. Clin. North Am., v.9, n.6, p.33-42, 1965.

09. CHAI, J. Y. et al. Adhesive properties of several impression materials systems: Part I. J. prosth. Dent., v.66, n.2, p.201-9, Aug. 1991. 
10. CIESCO, N. J. et al. Comparison of elastomeric impression materials used in fixed prosthodontics. J. prosth. Dent., v.45, n.1, p.89-94, Jan. 1981.

11. CLANCY, J.M.S.; SCANDRETT, F. R.; ETTINGER, R. L. Long-term dimensional stability of three current elastomers. J. oral Rehab., v.10, n.4, p.325-33, July 1983.

12. CORSO, M. et al. The effect of temperature changes on the dimensional stability of polyvinyl siloxane and polyether impression materials. J. prosth. Dent., v.79, n.6, p.626-31, June 1998.

13. DIMASHKIEH, M. R.; MORGANO, S. M. A procedure for making fixed prosthodontic impressions with the use of preformed crown shells. $\mathbf{J}$. prosth. Dent., v.73, n.1, p.95-96, Jan. 1995.

14. EAMES, et al. Elastomeric impression materials: effect of bulk on accuracy. J. prosth. Dent., v.41, n.3, p.304-07, Mar. 1979.

15. EAMES, et al. Accuracy and dimensional stability of elastomeric impression materials. J. prosth. Dent. V.42, n.2, p.159-62, Aug. 1979.

16. FARAH, J. W.; CLARK, A. E.; AINPOUR, P. R. Elastomeric impression materials. Oper. Dent., v.6, n.1, p.15-19, 1981.

17. GOMES DE SÁ, A. T.; FREITAS, C. A.; MARCHESE, M. P. Fidelidade de troquéis de gesso, obtidos a partir de moldes de um tipo de silicona de condensação, com 3 diferentes espessuras, utilizando casquetes de resina acrílica. Revista da Faculdade de Odontologia de Lins, v.13, n.2, p. 6468, 2001. 
18. LACY, A. M. et al. Time-dependent accuracy of elastomer impression materials. Part I: Condensation silicones. J. prosth. Dent., v.45, n.2, p.20915, Feb. 1981.

19. LACY, A. M. et al. Time-dependent accuracy of elastomer impression materials. Part II: Polyether, polysulfides and polyvinylsiloxane. J. prosth. Dent.., v.45, n.3, p.329-33, Mar. 1981.

20. MANTOVANI, R.S. Fidelidade morfo-dimensional de troquéis de 2 diferentes gessos tipo IV (Durone ${ }^{\circledR}$ e Vel-Mix ${ }^{\circledR}$ ), obtidos a partir de uma silicona de condensação (Oranwash ${ }^{\circledR}$ ), usando a técnica do casquete. Bauru, 2001, Dissertação (Mestrado) - Faculdade de Odontologia de Bauru, Universidade de São Paulo.

21. MARCHESE, M. P Dois métodos de avaliação da fidelidade morfodimensional de troquéis de gesso, obtidos a partir de moldes de elastômeros, com ou sem reaquecimento. Bauru, 1994. 129p. Dissertação (Mestrado) - Faculdade de Odontologia de Bauru, Universidade de São Paulo.

22. MARCHESE, M. P. Fidelidade de troquéis de gesso, obtidos a partir de moldes de vários elastômeros, através de duas diferentes técnicas de moldagem. Bauru, 1999. 162p. Tese (Doutorado) - Faculdade de Odontologia de Bauru, Universidade de São Paulo.

23. McCABE, J. F., STORER, R. Elastomeric impression materials: The measurement of some properties relevant to clinical practice. Brit. Dent. J., v.149, n.5, p.73-9, Aug. 1980. 
24. MOJON, P. et al. Polymerization shrinkage of index and pattern acrylic resins. J. prosth. Dent., v.64, n.6, p.684-88, Dec. 1990.

25. PAGNIANO, R.P. et al. Linear dimensional change of acrilic resins used in the fabrication of custom trays. J. prosth. Dent., v. 47, n.3, p.279-83, March 1982.

26. PHILLIPS, R. W. Physical properties and manipulation of rubber impression materials. J. Amer. Dent. Ass., v.59, p.454-58, Sep. 1959.

27. PIWOWARCZYK, A. et al. In vitro study on dimensional accuracy of selected materials for monophase elastic impression making. Int. $\mathbf{J}$. Prosthodont., v.15, n.2, p.168-74, 2002.

28. PRICE, B. R. et al. The dimensional accuracy of 12 impression material and die stone combination. Int. J. Prosthodont., v.4, n.2, p.169-74, 1991.

29. RAGAIN, J.C. et al. Detail reproduction, contact angles and die hardness of elastomeric impression and gypsum die material combinations. Int. $\mathbf{J}$. Prosthodont., v.13, n.3, p. 214-20, 2000.

30. SCHELB, E. et al. Compatibility of type IV dental stones with polyether impression materials. J. Prosth. Dent., v.60, n.5, p. 19-22, 1987.

31. SKINNER, C. W.; COOPER, E. N. Desirable properties and use of rubber impression materials. J. Amer. Dent. Ass., v.51, n.5, p.523-37, Nov. 1955.

32. VALDERHAUG, J.; FLÖYSTRAND, F. Dimensional stability of elastomeric impression materials in custom-made and stock trays. J. prosth. Dent., v.52, n.4, p.514-7, Oct. 1984. 
Abstract 


\section{Abstract}

The aim in this study was to evaluate the dimensional accuracy of dies made with a type IV stone $\left(\right.$ Vel-Mix $\left.{ }^{\circledR}\right)$ dies, obtained from moulds of a sole elastomer (Impregum $^{\circledR} \mathrm{F}$ ), by employing 2 different moulding techniques, with a shell or with a perforated stock tray. Stone dies accuracy was measured by means of a standard crown which could be accurately fitted to the standard die, the original structure to be moulded. In this way, the following 4 groups were stablished, with the mould heating not being done only in the first of them: 1- with the acrylic resin shell cervically not contacting the standard die; 2- with the refered shell but without that contact; 3- once more with the shell, again with that contact and 3- with the stock tray. Under the stablished conditions, after statistical treatment of results, the following conclusions could be drawn: 1- worst performance was presented by the stock tray, with a 397,70 $\mu \mathrm{m}$ mean inaccuracy; 2- the shell performance with cervical contact and heated $(85,37 \mu \mathrm{m}$ mean inaccuracy) was similar to that of it without contact and without heating $(102,38 \mu \mathrm{m}$ mean inaccuracy) and 3- better performance was presented by shell without contact and with heating, with a 0,03 $\mu \mathrm{m}$ mean inaccuracy. 